\title{
A LABORATORY EXAMINATION OF EMOTION REGULATION SKILL STRENGTHENING IN BORDERLINE PERSONALITY DISORDER \\ by
}

Rebecca Kathleen Metcalfe B.A.,

McGill University, 2010

\author{
A thesis \\ presented to Ryerson University \\ in partial fulfillment of the \\ requirements for the degree of \\ Master of Arts \\ in the Program of \\ Psychology
}

Toronto, Ontario, Canada, 2015

CRebecca Metcalfe, 2015 


\section{AUTHOR'S DECLARATION FOR ELECTRONIC SUBMISSION OF A THESIS}

I hereby declare that I am the sole author of this thesis. This is a true copy of the thesis, including any required final revisions, as accepted by my examiners.

I authorize Ryerson University to lend this thesis to other institutions or individuals for the purpose of scholarly research.

I further authorize Ryerson University to reproduce this thesis by photocopying or by other means, in total or in part, at the request of other institutions or individuals for the purpose of scholarly research. I understand that my thesis may be made electronically available to the public. 
A Laboratory Examination of Emotion Regulation Skill Strengthening in Borderline Personality

Disorder

Rebecca Kathleen Metcalfe B.A.,

McGill University, 2010

in partial fulfillment of the requirements for the degree of Master of Arts in Psychology

Ryerson University, 2015

\begin{abstract}
The present study examined emotion regulation skill strengthening among individuals with borderline personality disorder (BPD) compared to healthy controls (HCs). Participants were instructed to repeatedly implement two emotion regulation strategies (i.e., distraction and mindful awareness) in response to BPD-relevant stimuli across multiple trials. Throughout the task, both self-reported negativity and positivity, and physiological indices of emotion (i.e., heart rate and skin conductance response) were collected. Results indicated that individuals with BPD and HCs displayed improvements in distraction compared to the control condition, but not in mindful awareness over time. When comparing the two emotion regulation strategies to each other, rate of skill strengthening varied by group. Specifically, HCs evidenced improvements in distraction. In contrast, individuals with BPD evidenced improvements in mindful awareness. These findings suggest that individuals with BPD do not show deficits in skill strengthening as compared to HCs.
\end{abstract}




\section{Acknowledgements}

A thesis is an exciting and simultaneously daunting undertaking. I am fortunate to have had support to keep me level-headed during the exciting times, and motivated during the daunting ones.

First and foremost I would like to thank my supervisory and defense committee members, Dr. Naomi Koerner and Dr. Colleen Carney. Their support and guidance throughout my master's degree has been invaluable. Additionally, Dr. Koerner's rigor and careful feedback greatly enhanced the strength of this thesis.

Second, I am immensely grateful to my supervisor, Dr. Janice Kuo. Dr. Kuo’s mentorship helped me develop immeasurably into a critical thinker and a careful writer. She is a thoughtful, erudite, and judicious academic, and I am fortunate to have had the privilege of Dr. Kuo's mentorship over the past years.

I would also like to thank my family and friends for their ongoing support. I am the lucky receiver of many delicious meals, and warm hugs. My parents and sister have been wonderful through every step of my graduate career. If only others could be so lucky as to know such unwavering support.

Finally, I would like to thank members of the Borderline Personality Disorder and Emotion Processing Laboratory for their hard work and feedback both on this project, and others. Additionally, I would like to thank the members of my cohort for the thought-provoking discussions, and unending laughter. 
Table of Contents

CHAPTER I: Introduction

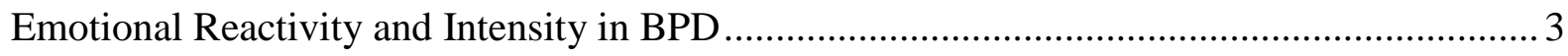

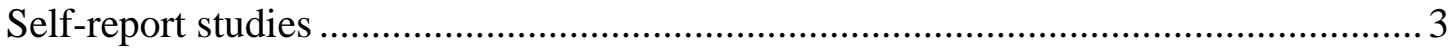

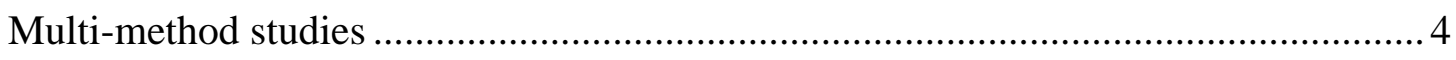

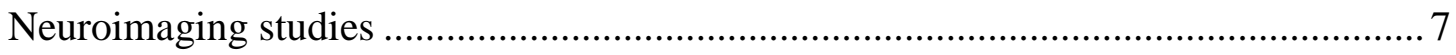

Treatment of BPD: Decreasing Emotional Intensity …............................................. 9

Two Core Emotion Regulation Skills Taught in DBT: Distraction and Mindful Awareness ... 11

Distraction and Mindful Awareness in Other Populations ............................................... 12

Distraction and Mindful Awareness in BPD ......................................................... 15

Emotion Regulation in BPD: Is the Deficit in Skill Strengthening? .................................. 17

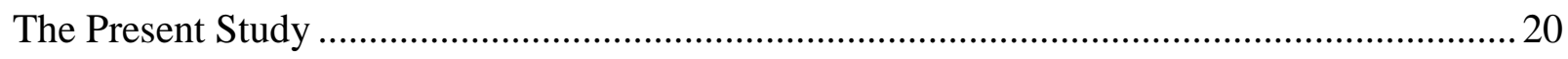

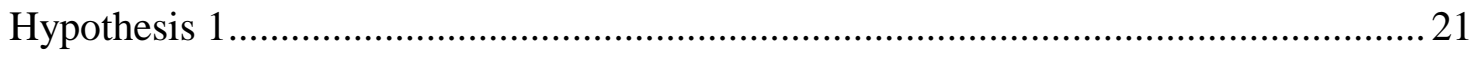

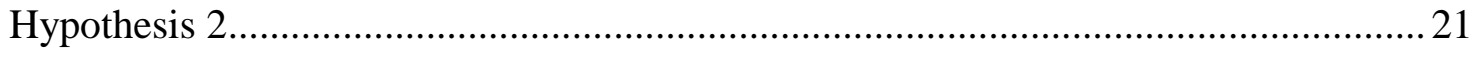

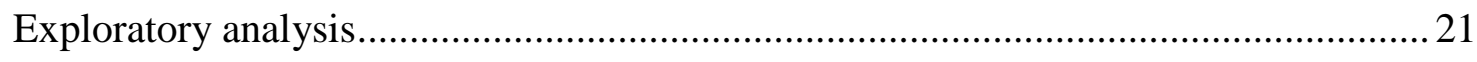

CHAPTER II: Method

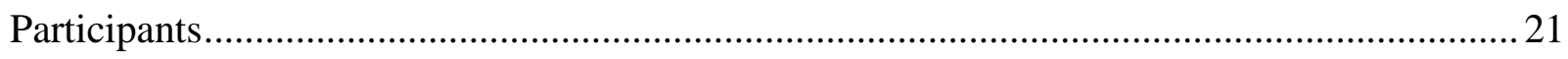

Screening and Assessment Procedures ................................................................... 23

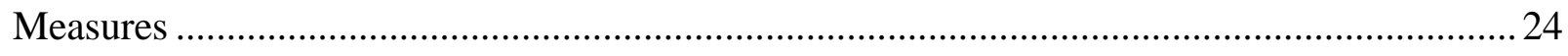

Screening and descriptive measures ........................................................... 24

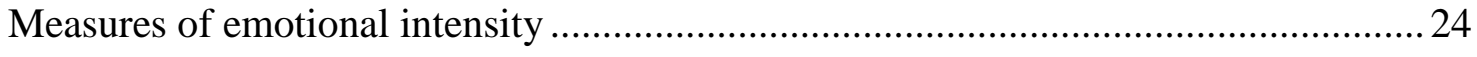

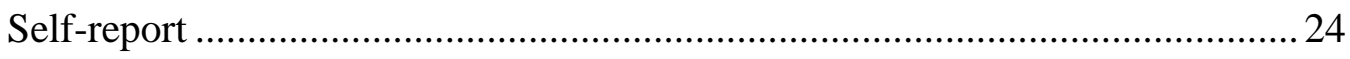

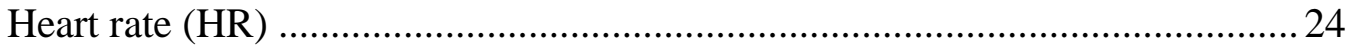


Skin conductance level (SCL)

Emotionally evocative images ..................................................................... 25

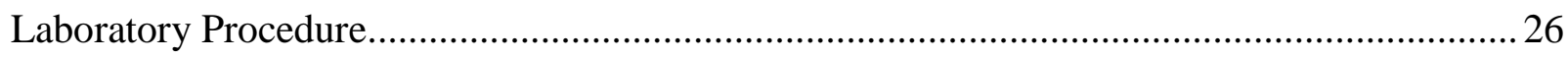

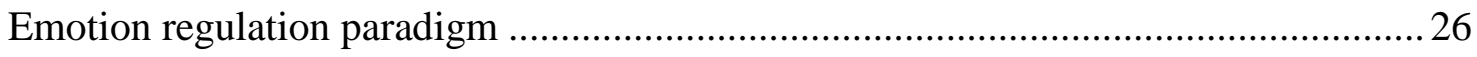

Training and practice phase ................................................................ 26

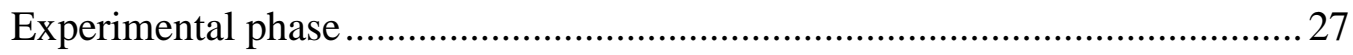

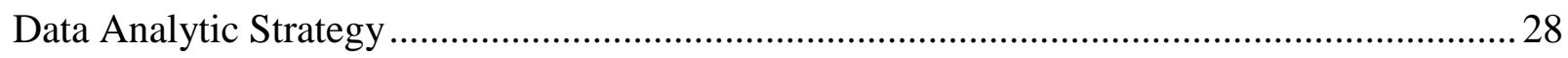

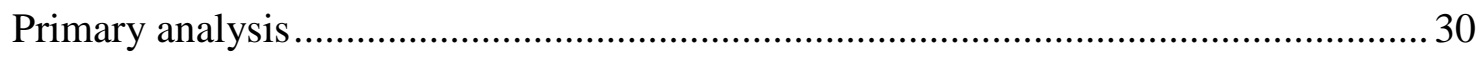

Hypothesis 1 and 2: Skill strengthening among individuals with BPD and HCs ......... 31

Exploratory analysis: Examining the relationship between emotion regulation

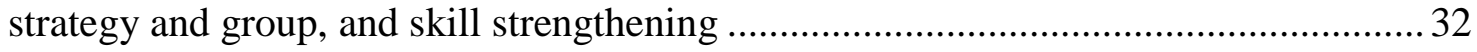

CHAPTER III: Results

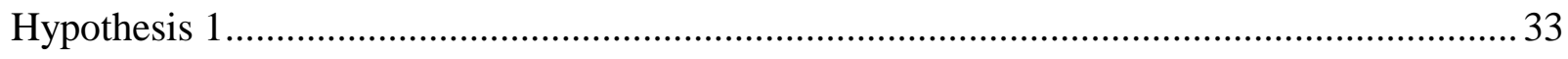

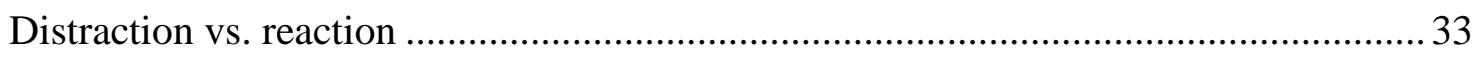

Mindful awareness vs. reaction................................................................. 33

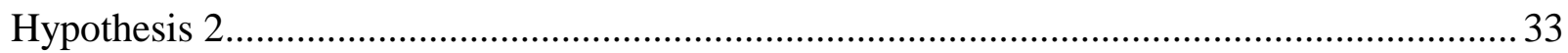

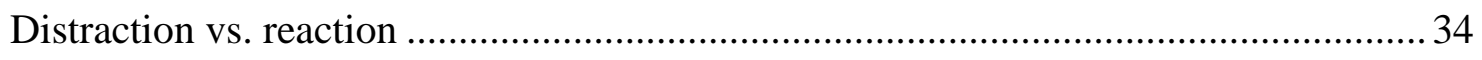

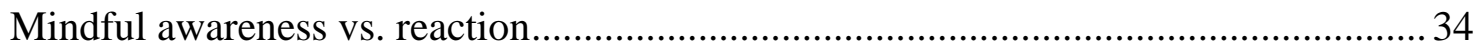

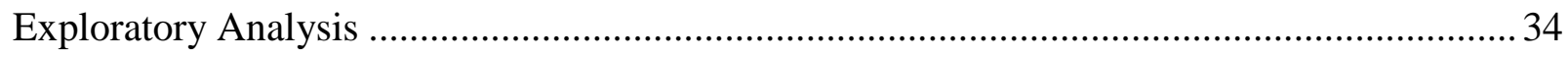

Distraction vs. mindful awareness ............................................................... 34

CHAPTER IV: Discussion

Hypothesis 1: General Skill Strengthening Across Groups ............................................. 35

Hypothesis 2: Delayed Skill Strengthening Among Individuals with BPD .......................... 37 
Exploratory Analysis: Does Rate of Skill Strengthening in Each Group Vary by Emotion

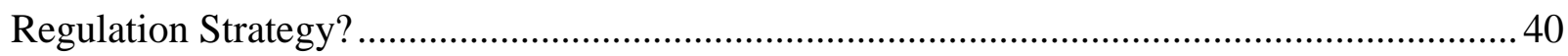

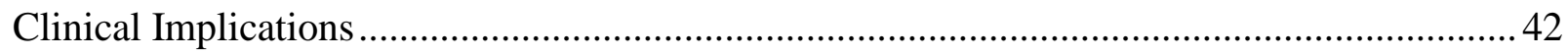

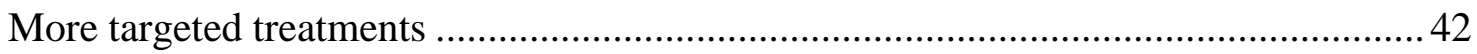

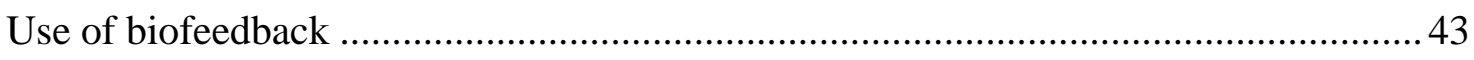

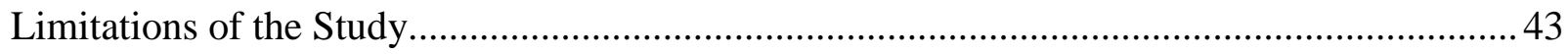

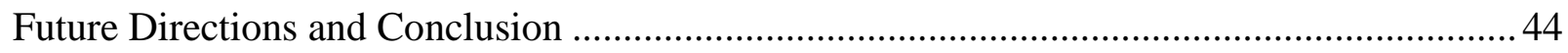

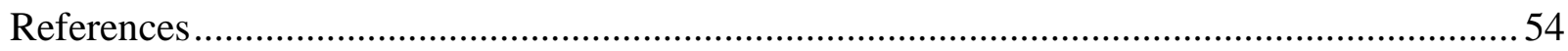




\section{List of Tables}

Table 1: Past and Current Axis I Diagnoses in the Borderline Personality Disorder Group..... 47

Table 2: Participant Demographics by Diagnostic Status............................................... 48

Table 3: Hierarchical Linear Modeling Fixed Effects for the Pairwise Comparison of

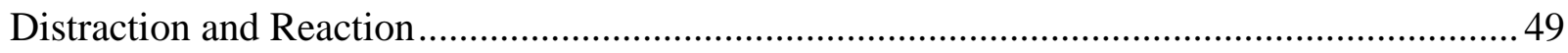

Table 4: Hierarchical Linear Modeling Fixed Effects for the Pairwise Comparison of

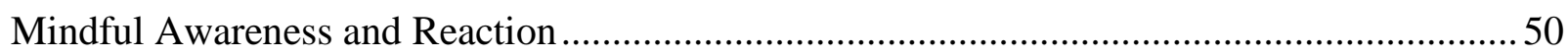

Table 5: Hierarchical Linear Modeling Fixed Effects for the Pairwise Comparison of

Distraction and Mindful Awareness ............................................................................ 51

Table 6: Means and Standard Deviations for the First and Last Segments of Each Condition

for Each Outcome Variable, by Diagnostic Status .......................................................... 52 


\section{List of Figures}

Figure 1: Schematic Illustration of a Participant's Experimental Trial .................................53 
A Laboratory Examination of Emotion Regulation Skill Strengthening in Borderline Personality

\section{Disorder}

Borderline personality disorder (BPD) is a pervasive and complex psychological disorder characterized by extreme behavioural, emotional, and cognitive distress (American Psychiatric Association, 2013; Linehan, 1993). Key components of BPD include emotion dysregulation, unstable interpersonal relationships, impulsivity, recurrent suicide attempts, non-suicidal selfinjury (NSSI), and identity disturbance (American Psychiatric Association, 2013). Although the prevalence of BPD in the population is estimated at between 0.5 and 5.7\% (Grant et al., 2008; Coid, Yang, Tyrer, Roberts \& Ullrich, 2006; Jackson \& Burgess, 2000), individuals with BPD comprise $10 \%$ of outpatient mental health users and between $20 \%$ and $40 \%$ of inpatient mental health users (Geller, 1986; Grant et al., 2008; Lieb, Zanarini, Schmahl, Linehan \& Bohus, 2004). The conjunction of high prevalence and severe impairment associated with the disorder make BPD an expensive disorder to treat; in Canada, treatment of BPD costs between $\$ 20,000$ and $\$ 50,000$ per year per individual (Van Busschbach, 2012).

In addition to high healthcare costs, BPD is associated with high human costs. Eightyfour percent of individuals with BPD engage in self-harm (Soloff, Lynch \& Kelly, 2002), and approximately $8 \%$ commit suicide — a rate which is 50 times higher than that of the general population (American Psychiatric Association, 2013; Pompili, Girardi, Ruberto, \& Tatarelli, 2005). BPD is also associated with high comorbidity with other psychological disorders (Grant et al., 2008; Zanarini et al., 1998; Zanarini et al., 1999), with the average individual with BPD meeting criteria for four other diagnoses (McGlashan et al., 2000). These comorbidities are especially prevalent across mood and anxiety disorders, with $75 \%$ to $80 \%$ of individuals with 
BPD reporting at least one lifetime mood disorder, and $74.2 \%$ to $90 \%$ reporting at least one lifetime anxiety disorder (Grant et al., 2008; Zanarini et al., 1998).

Although several models of BPD and its causal and maintaining factors have been proposed (see Fonagy, Target \& Gergely, 2000; Judd \& McGlashan, 2003), Linehan’s Biosocial Model is one of the most clearly delineated (Crowell, Beauchaine \& Linehan, 2009; Lieb et al., 2004; Linehan, 1993). At its crux, Linehan's theory follows a transactional model and posits that BPD results from the transaction between an individual's biological vulnerability to high emotionality (i.e., difficulty with emotion regulation, low distress tolerance) and an invalidating environment during early development. An invalidating environment is one in which " $[t]$ he individual's private experiences and emotional expressions are not viewed as valid responses to events," (Linehan, 1993, pp. 50) and response to the expression of private emotional experiences is inconsistent, unpredictable and inappropriate. Consequently, the individual learns that these emotional experiences result from socially unacceptable personality traits or characteristics that the individual possesses, and that when the individual does communicate private experiences, emotional responses must be extreme in order to receive validation. The transaction between the invalidating environment and the individual's biological vulnerability prevents the individual from learning appropriate emotion regulation strategies, and lowers distress tolerance.

Substantiating Linehan's theory, pervasive difficulty with emotion regulation has been identified as the primary mechanism that may underlie the features of BPD (Linehan, 1993; Putnam \& Silk, 2005). Two core components of difficulties with emotion regulation specified in Linehan's (1993) model that have received substantial empirical attention are heightened emotional intensity (i.e., general elevations in the intensity of emotion experienced) and heightened emotional reactivity (i.e., changes or fluctuations in emotional intensity in response 
to an emotionally-salient stimulus). Consistent with this model, qualitative studies of BPD have used descriptors of emotional intensity such as "destructive whirlwind" (Woollaston \& Hixenbaugh, 2008 p. 703); and "volcano" (Perseius, Ekdahl, Åsberg \& Samuelsson, 2005 p. 160). A 2005 study (Conklin \& Westen) compared descriptors of other clinical groups with individuals with BPD and found that individuals with BPD were uniquely described as having emotions that "tend to spiral out of control" (p. 872). However, of note, because elevated baseline emotional intensity may not be apparent until a stressor is encountered, clinical observations may conflate increased emotional reactivity with increased emotional intensity. Indeed, as will be reviewed below, although empirical studies largely support the presence of increased emotional intensity among individuals with BPD, data on increased emotional reactivity are inconsistent.

\section{Emotional Reactivity and Intensity in BPD}

Self-report studies. Many empirical studies have used questionnaire or self-report measures to assess emotional responding among individuals with BPD. However, because of the nature of these questionnaires, these studies primarily assess information on general levels of emotional intensity, rather than changes in intensity, i.e., reactivity. To date, empirical studies using selfreport measures have consistently found that individuals with BPD report more intense negative emotions than healthy controls (HCs) (e.g. Conklin, Bradley \& Westen, 2006; Glenn \& Klonsky, 2009; Yen, Zlotnick \& Costello, 2002). For example, using the affect intensity measure (AIM) Levine, Marziali, and Hood (1997) compared individuals with BPD to individuals without the disorder (i.e., both HCs and individuals with other disorders) on the intensity of their responses to negative emotions. The AIM asks individuals to rate the intensity of their emotion reactions to 40 ordinary life events. Compared to individuals without BPD, those with BPD reported 
significantly greater intensity of negative emotions. Furthermore, these findings are corroborated in both laboratory and naturalistic settings. Ebner-Priemer and colleagues (2007) used an ambulatory monitoring methodology to assess self-reported emotional intensity in participants' natural environment, and found that individuals with BPD reported both greater emotional distress and more intense negative mood states than HCs.

Multi-method studies. Unlike self-report studies, several multi-method laboratory studies have investigated both emotional intensity and emotional reactivity simultaneously. These studies have largely found support for elevated emotional intensity, but not for heightened emotional reactivity among individuals with BPD. Gratz, Rosenthal, Tull, Lejuez, and Gunderson (2010) asked participants with BPD to rate their levels of anxiety, irritability, hostility, and shame at five time points while completing a negative feedback task designed to evoke emotional distress. Findings indicated that the BPD group exhibited elevated emotional intensity throughout the task compared to individuals from a clinical population without a personality disorder. However, after controlling for elevated baseline emotional responses, there were no differences between individuals with BPD and clinical controls in anxiety, hostility, or irritability throughout the trial. In other words, individuals with BPD showed elevated emotional intensity, but did not show heightened emotional reactivity compared to psychiatric controls. However, individuals with BPD reported significantly more shame throughout the task.

Similarly, Kuo and Linehan (2009) used a multi-method design to examine emotional reactivity to both idiographic (a personal script) and standardized (a film segment) stimuli aimed at eliciting sad, angry, fearful, and neutral emotional responses. Individuals with BPD, social anxiety disorder (SAD), and healthy controls (HCs) were exposed to each of the 8 stimuli a single time. Like the study by Gratz and colleagues (2010), when examining change from 
baseline emotional responding following presentation of the stimuli, individuals with BPD did not display heightened emotion reactivity compared to individuals SAD and HCs. However, individuals with BPD displayed a higher baseline emotional intensity than HCs and individuals with SAD. This finding was consistent across measures including self-ratings of emotional response, skin conductance response, and respiratory sinus arrhythmia. Moreover, individuals with SAD and HCs showed increased skin conductance responses during the sad film stimulus, whereas individuals with BPD showed no change.

Elices and colleagues (2012) used self-report and physiological measures (i.e. skin conductance level, and heart rate) to evaluate emotional responses to six film clips aimed at eliciting a variety of emotional responses (e.g., sadness, anger, fear, and disgust). Similar to findings by Kuo and colleagues (2009), findings indicated that individuals with BPD reported higher negative emotions at baseline than HCs, but were no different than HCs on emotional reactivity across film conditions. The authors concluded that increased negative emotional intensity, rather than heighten emotional reactivity, may be the core feature of BPD.

Most recently, Scott, Levy, and Granger (2013) assessed emotional intensity and reactivity by measuring changes in self-reported emotional responding, cortisol, and alphaamylase in response to a psychosocial stressors (e.g., a public speaking task). Individuals with BPD were compared to individuals who had similar scores on trait measures of negative affect and impulsivity (i.e., trait-matched), and to individuals with lower scores on those same measures (i.e., non-trait-matched). Compared to both non-trait-matched and trait-matched controls, individuals with BPD displayed higher baseline and overall self-reported negative affect, and higher baseline cortisol levels, indicating high emotional intensity and high baseline 
emotional arousal. In contrast, there were no differences between individuals with BPD and the two control groups on emotional reactivity.

Of note, one study using multi-method indices (e.g. physiological measurements and selfreport) did not find support for heightened emotional intensity among individuals with BPD. Herpertz, Kunert, Schwenger, and Sass (1999) used self-report, skin conductance, heart rate, and startle response to measure emotional intensity in response to 6 unpleasant images, 6 neutral images, and 6 pleasant images among 24 individuals with BPD and 27 HCs. After controlling for trait impulsivity and aggressiveness, individuals with BPD did not show greater emotional intensity across all three conditions. Instead, the converse was found; individuals with BPD showed lower skin-conductance responses (i.e. less emotional intensity) across all three image conditions than individuals with no diagnosis. The authors did not examine emotional reactivity. This incongruence in findings is potentially due to the type of stimuli used. Herpertz and colleagues (1999) used standardized images with content that varied both between and within image categories (e.g., some of the pleasant images included sports scenes and romantic images, whereas some of the unpleasant images included aimed guns and wild animals attacking). Recent research indicates that individuals with BPD are differentially responsive to different themes in the content of stimuli. Specifically, individuals with BPD show more intense emotional responses to disorder-specific stimuli (e.g. scenes of rejection and abandonment) than HCs but do not show more intense reactions to non-disorder specific stimuli (e.g. standard unpleasant scripts) than HCs (Limberg, Barnow, Freyberger, and Hamm, 2011). Furthermore, individuals with BPD are differentially reactive to different types of stimuli (e.g. heightened sensitivity to facial expressions; more responsive to auditory stimuli than visual stimuli; Rosenthal, Roianne, \& Geiger, 2011); thus, studies using stimuli with an auditory component (e.g. films) may yield 
different findings from those using stimuli that is solely visual (e.g. images). Furthermore, within visual stimuli, those using images depicting facial expressions and disorder-specific themes may yield different results than those using other content (Lynch et al., 2006). Thus, the conflict between Herpertz and colleagues (1999) findings and more recent studies may be due to the use of standardized images that did not include a disorder specific component, an auditory component, or facial expressions - all of which have been found to evoke emotional responses from individuals with BPD.

Neuroimaging studies. In contrast to findings from studies using self-report and peripheral physiological measures, neuroimaging research on emotional reactivity in individuals with BPD has generally supported Linehan's (1993) theory. Functional magnetic resonance imaging (fMRI) is a tool commonly used to measure neural activation. FMRI studies compare changes in activation (i.e., the difference between activation at baseline and activation during stimulus presentation) between two groups. Thus, fMRI studies are well suited to examine emotional reactivity but not emotional intensity.

Multiple studies have used fMRI to examine amygdala activation in response to stimuli among individuals with BPD (see Rosenthal et al., 2008 for a review). Amygdala activation is of particular significance as research shows that the amygdala is the primary brain structure involved in stress and emotion responses (Davidson, 2002; Davis \& Whalen, 2001; Gallagher \& Chiba, 1996; Roozendaal, McEwen, \& Chattarji, 2009). Using fMRI, Herpertz and colleagues (2001) compared amygdala reactivity in response to 12 neutral and 12 unpleasant images among six individuals with BPD and six HCs. Findings indicated that individuals with BPD exhibited significantly greater bilateral amygdala reactivity following exposure to negative images than did HCs. Building on these results, Donegan and colleagues (2003) examined amygdala activation in 
response to presentation of blocks of neutral, happy, sad, or fearful facial expressions, or a fixation cross. Each block contained only one type of facial expression (e.g., sad) and lasted for 20-seconds. Analysis revealed that individuals with BPD had significantly greater left amygdala activation following exposure to facial expressions of emotion than healthy controls did. Given the link drawn between the amygdala and stress, anxiety, and emotional responding (Davidson, 2002; Davis \& Whalen, 2001), findings from these studies indicate that individuals with BPD may show increased reactivity to emotionally salient stimuli.

In sum, laboratory studies examining emotional reactivity in individuals with BPD have found mixed results. Contrary to Linehan's (1993) theory that individuals with BPD have heightened emotional reactivity, studies using physiological and self-report measures of emotion reactivity have found that individuals with BPD are no different from HCs (e.g. Elices et al., 2012; Kuo \& Linehan, 2009). Studies using neuroimaging techniques, on the other hand, have broadly supported the biosocial theory (1993), and have found increased emotional reactivity among individuals with BPD as compared to HCs (e.g. Donegan et al., 2003; Herpertz et al., 2001). These conflicting findings may be due to differences in measurement type (e.g. skin conductance response, as compared to fMRI), or study methodology. Furthermore, this discordance between measures could itself be evidence that stimuli were not sufficiently arousing; Rachman and Hodgeson (1974) posit that discordance between measures decreases as a function of emotional intensity.

In contrast to studies of emotional reactivity, investigations of elevated emotional intensity in BPD have largely supported the emotion dysregulation component of the biosocial model. Across self-report (e.g., Levine, Marziali \& Hood, 1997), and peripheral psychophysiological measures (e.g., Gratz et al., 2010) individuals with BPD have displayed 
heightened emotional intensity compared to both clinical controls and HCs. Consequently, researchers have concluded that this elevated emotional intensity alone may be sufficient to cause the difficulties with emotion regulation evident in individuals with BPD (Schmahl et al., 2014). These conclusions lend support to current BPD treatments which focus on modulating emotional intensity by improving emotion regulation skills.

\section{Treatment of BPD: Decreasing Emotional Intensity}

Given the conjunction of clinical observations and empirical support for heightened emotional intensity among individuals with BPD, treatment efforts have largely focused on reducing or regulating emotional intensity. Dialectical behaviour therapy (DBT; Linehan, 1993) is the most empirically supported treatment for BPD with nine randomized clinical trials (Carter et al., 2012; Clarkin, Levy, Lezenweger, \& Kernberg, 2007; Linehan, et al, 1991, 1999, 2002, 2006; McMain et al., 2009, 2012; Verheul et al., 2003) demonstrating its efficacy at reducing NSSI, suicide attempts, and inpatient psychiatric hospital stays (for reviews see Robins \& Chapman, 2004; Zanarini, 2009). Furthermore, a recent study of amygdala activation suggests that DBT does in fact improve BPD symptoms by attenuating emotional intensity. Using fMRI, Goodman and colleagues (2014) measured amygdala activation in response to pleasant, neutral, and unpleasant images. Compared to HCs to control for training effects, individuals with BPD showed decreased overall amygdala activation (i.e., decreased intensity of activation) following 12-months of standard DBT. Complementing these physiological findings, individuals with BPD reported improved emotion regulation as measured by the Difficulties with Emotion Regulation Scale (DERS). Furthermore, reductions in amygdala activity were positively correlated with DERS-measured improvements in emotion regulation. 
DBT is based on the assumption that characteristics of BPD are either a direct outcome of emotion dysregulation (e.g., extreme anger), or function to regulate heightened emotional intensity (e.g., self-harm) (Linehan, 1993). Standard DBT is based on a skills deficit model and is a multimodal treatment composed of 4 treatment modes: individual behaviour therapy; group skills training; 24-hour phone coaching; and weekly consultation team meetings for the therapists. Each DBT mode serves a different function in order to provide a comprehensive treatment package. The group skills training component targets skills acquisition, skill strengthening, and skill generalization. Thus, group skills training includes not only in-session practice (i.e., skill acquisition and skill strengthening), but additional homework to practice newly acquired skills (i.e., skill strengthening and generalization) as well. The predominant emphasis of skills training is improving emotion regulation, which includes reducing or modifying emotional intensity. Indeed, three of the four skills training modules-emotion regulation, distress tolerance, and mindfulness modules - target emotion regulation. Although categorized as separate from the emotion regulation module, the distress tolerance and mindfulness modules also focus on explicit emotion regulation skills. DBT separates distress tolerance and mindfulness modules from the emotion regulation module in order to emphasize the specific instances where these skills are particularly effective. For example, distress tolerance skills are designed to triage instances in which an individual experiences an intense and potentially overwhelming degree of emotional distress. In contrast, mindfulness module skills include a more global approach that attempts to decrease the likelihood of intense moments of emotion dysregulation. In sum, then, DBT skills training aims to improve BPD features by teaching and strengthening skills to rectify difficulties regulating high intensity emotional responses. 


\section{Two Core Emotion Regulation Skills Taught in DBT: Distraction and Mindful Awareness}

Two key skills taught in the DBT skills modules are distraction, a distress tolerance skill; and mindful awareness, an acceptance-based skill derived from the principles of zen-buddhism. Although the two skills theoretically work through different means, they both have the same end goal-facilitating emotion regulation. Distraction is a technique whereby the individual both "produces neutral thoughts" and directs attention away from the emotionally salient aspects of the distressing stimulus (Sheppes, Scheibe, Suri, \& Gross, 2011, p. 1392; Urry, 2010). Consequently, distraction is considered a disengagement strategy. Both research and theory suggest that distraction provides an immediate change of the emotion experience (Gross, 2002; Thiruchselvam, Blechert, Sheppes, Rydstrom \& Gross, 2011). In contrast to the disengagement strategy of distraction, mindful awareness has been described as a presence of mind that arises when one attends to — and engages with—-moment-to-moment experience (Bishop et al., 2004; Kabat-Zinn, 1990). Mindful awareness has further been conceptualized as consisting of two components: self-regulation of attention to maintain focus on the present experience; and an orientation towards that experience which is characterized by acceptance (Bishop et al., 2004). When practicing mindful awareness, the individual "is instructed to make an effort to just take notice of each thought, feeling, and sensation that arises in the stream of consciousness" (Bishop et al., 2004, p. 233). Thus, in contrast to distraction, mindful awareness is a strategy that entails deploying attention towards distressing stimuli and negative emotions. For this reason, mindfulness awareness is often referred to as an engagement, or approach, strategy (Hayes \& Feldman, 2004). Whereas disengagement strategies (i.e., distraction) focus on avoiding emotion experiences, engagement strategies (i.e., mindful awareness) focus on noticing and engaging with the emotional experience without judgment. When used to temper emotional arousal, 
distraction has been shown to work more quickly than engagement strategies (Thiruchselvam, Blechert, Sheppes, Rydstrom \& Gross, 2011). According to Gross's (2002) process model of emotion regulation, both disengagement and engagement strategies are necessary for optimal and adaptive emotion regulation. Furthermore, the appropriateness of these strategies varies by context (i.e., level of distress). The DBT module division reflects this variation: the distress tolerance skills teach disengagement strategies for high distress situations; and the mindfulness and emotion regulation modules teach engagement strategies for low distress situations. In DBT, both distraction and mindful awareness are taught and practiced throughout the duration of treatment. Indeed, research indicates that of the 19 primary skills taught in DBT, distraction and mindful awareness are employed the most by individuals receiving DBT treatment (Lindenboim, Comtois, \& Linehan, 2007).

\section{Distraction and Mindful Awareness in Other Populations}

Research from basic affective science examining distraction and mindful awareness following negative mood inductions has generally found these strategies to be effective. Broderick (2005) compared the effect of rumination $(n=55)$, distraction $(n=61)$, and mindfulness meditation $(n=61)$ on negative affect following a negative mood induction in 177 undergraduate students. Individuals in the rumination and distraction conditions were instructed to focus on self-reflective statements (e.g., "why do you react the way you do") or non-selfdirected statements (e.g., “a freshly painted door”), respectively (Broderick, 2005, p. 504). Individuals assigned to mindfulness meditation were instructed to focus on self-acceptance and awareness of breath, a practice adapted from a meditation script developed by Kabat-Zinn (Broderick, 2005). Individuals assigned to the mindfulness meditation condition reported significantly lower levels of negative mood than did those in the distraction $(d=.29)$ or 
rumination $(d=.91)$ conditions, and distraction was found to decrease negative affect significantly more than rumination $(d=.67)$. Notably, the authors did not report a significant increase in negative affect in those assigned to the rumination condition. In partial conflict with these findings, Kuehner, Huffziger, and Liebsch (2009) compared the same three conditions in an undergraduate sample following a negative mood induction and found that distraction improved negative affect compared to both mindful-meditation $(d=.42)$ and rumination $(d=1)$, neither of which were associated with significant improvements $(p>.05)$. The authors suggested that the discrepancy in findings may be due to methodological differences in the mindfulness induction (i.e., Broderick (2005) used audiotapes to guide attention whereas Kuehner and colleagues (2009) did not).

Likewise, research using other experimental paradigms in HCs has strongly supported the efficacy of both mindful awareness and distraction in regulating emotional responding. For example, Braams, Blechert, Boden, and Gross (2012) used both self-report and physiological measures to compare the effects of suppression (a disengagement strategy in which individuals try to inhibit emotional responses), acceptance (one component of mindful awareness), and no instruction on anticipation and receipt of painful shock stimulation. Both acceptance and suppression led to similar reductions in subjective pain reports, cardiac responses to anticipation of pain, and cardiac responses to pain relative to the no instruction condition. Acceptance, however, was uniquely associated with lowered subjective anticipatory anxiety. Arch and Craske (2006) reported similar findings following exposure to negative images. Individuals were assigned to one of three conditions: mindful awareness; unfocused attention (i.e. instructed to think about whatever came to mind); or worrying. Individuals in the mindful awareness condition, as opposed to the unfocused attention and worrying conditions, reported lower 
negative affect (partial $\eta^{2}=.03, .07$, respectively), lower emotional volatility, and greater willingness to view aversive stimuli during the task. Similar results have been found after individuals complete an impromptu anxiety provoking task (Hofmann, Heering, Sawyer, \& Asnaani, 2009).

Likewise, research in clinical populations strongly supports the effectiveness of both engagement and disengagement strategies across multiple experimental paradigms. Two separate studies examined the effectiveness of mindful awareness and distraction following a negative mood induction among individuals with remitted severe major depressive disorder and found both strategies were equally effective in decreasing negative affect (Huffziger \& Kuehner, 2009; Singer \& Dobson, 2007). Similarly, Campbell-Sills and colleagues (2006) compared the effects of suppression and acceptance on subjective and physiological emotional responding in a sample of 60 participants with anxiety and mood disorders. Participants were assigned to either suppress or accept emotions while watching a film clip validated to elicit anxiety-spectrum emotions. Those assigned to acceptance displayed decreased negative affect in the post-film recovery period, and a decreased heart rate in response to the film. In contrast, those in the suppression condition reported increased negative affect in the post-film recovery period, and an increased heart rate in response to the film. Although Campbell-Sills and colleagues (2006) did not examine distraction specifically, theory (e.g., Gross, 2002) and results from other studies (e.g., Huffziger \& Kuehner, 2009) indicate that findings about one strategy likely apply to other similar strategies (i.e., other disengagement strategies).

In sum, extant evidence from the basic emotion literature suggests that mindful awareness and distraction can be effective in both clinical and nonclinical populations in response to various types of negative stimuli. 


\section{Distraction and Mindful Awareness in BPD}

Although extensive research has been conducted on the use of mindful awareness and distraction in general, little research has explicitly examined the use of these skills among individuals with BPD. Given theoretical models of BPD as resulting from the conjunction of intense emotional reactions with emotion regulation deficits, it is interesting that emerging research indicates that individuals with BPD may be able acquire emotion regulation skills, including both engagement (e.g., mindful awareness) and disengagement (e.g., distraction) skills. The ability to acquire emotion regulation skills is significant because it suggests that individuals with BPD are not incapable of regulating emotions, but rather that emotion regulation skills may be under-developed relative to the intensity of their emotional experiences. Thus, emotion regulation skill acquisition may be one pathway to address difficulties experienced by individuals with BPD. In a sample of 17 individuals with BPD, Jacob and colleagues (2011) compared the effect of distraction, two imagery strategies, and a neutral task on emotional responses to both negative and neutral films. The distraction task required participants to complete an increasingly difficult number series; the imagery strategies required participants to think of either a positive autobiographical memory, or a non-autobiographical soothing image (e.g. being soothed by a close friend); the neutral task required participants to count the number of times the screen changed colour. All participants completed each strategy twice—once while viewing a negative film, and once while viewing a neutral film. Each of the four strategies resulted in decreased negative emotions following the negative film except for the neutral task which was not associated with any change. These findings indicate that individuals with BPD are able to acquire and implement emotion regulation strategies upon instruction. However, the implications of the study are limited as: 1) it is unclear if strategy effectiveness is dependent on, 
or related to stimuli type (e.g. imagined as opposed to visual); and 2) given the absence of a control group, it is unknown whether or not differences exist between individuals with BPD and HCs in implementation of emotion regulation skills. Further research comparing individual with BPD to HCs is needed to determine whether or not findings from one population are applicable to the other.

Though not a direct examination of distraction or mindful awareness, cortical activation studies examining the implementation of an engagement emotion regulation strategy indicate the individuals with BPD are able to acquire other emotion regulation skills. Marissen, Meuleman, and Franken (2010) found that, although individuals with BPD displayed greater cortical activation in response to aversive stimuli, they did not differ in emotional cortical reactivity when implementing cognitive reappraisal—an engagement strategy in which the individual attends to the aversive stimulus but changes something about its meaning to make the stimulus less distressing. Consistent with these findings, Ruocco, Medaglia, Ayaz and Chute (2010) found that, although individuals with BPD showed differential patterns of cortical activation when responding naturally to stimuli, individuals with BPD and matched healthy controls both recruited homologous regions of the prefrontal cortex when using cognitive reappraisal.

In contrast, Lang and colleagues (2012) used fMRI to examine anterior cingulate cortex (ACC) activity during reappraisal of negative auditory scripts. Results showed that compared to HCs, trauma-exposed individuals with BPD showed reduced activation of the ACC during reappraisal. However, trauma-exposed individuals with BPD did not differ from trauma-exposed HCs on ACC activation when implementing reappraisal. Thus the reported difference between trauma-exposed individuals with BPD and HCs without trauma exposure may be due to trauma exposure rather than BPD. Similarly, a 2009 study (Koenigsberg et al.) found that individuals 
with BPD, as compared to HCs, show a different pattern of activation when implementing reappraisal. The authors, however, did not speculate as to whether or not these differences were indicative of emotion regulation deficits. Thus, data indicate that individuals with BPD may show a differential emotional response at the neurological level. These data are unclear, however, as they do not indicate if these differences are specific to BPD or are caused by other factors (e.g., trauma-exposure). Furthermore, the impact of these neurological differences is unknown. Specifically, differences in neural activation may simply indicate different pathways to successful emotion regulation implementation rather than indicating a deficit in strategy implementation.

In sum, although research on the engagement of specific emotion regulation strategies in BPD has been sparse, a few studies indicate that individuals with BPD may be able to acquire and implement emotion regulation skills in much the same way that individuals from other populations can, suggesting that difficulties with emotion regulation in individuals with BPD may be remedied by training in emotion regulation skills.

\section{Emotion Regulation in BPD: Is the Deficit in Skill Strengthening?}

Although extant data suggest individuals with BPD might not exhibit deficits in skill acquisition (i.e., the ability to implement a skill upon instruction), no studies to date have examined whether this group exhibits deficits in skill strengthening. This difference between acquisition and strengthening is subtle but important. For example, given that individuals with BPD are characterized by heightened emotional intensity, the proficiency associated with initial skill acquisition may not be sufficient to modulate their emotions effectively. Thus, though the studies reviewed above suggest that individuals with BPD may be able to implement or acquire an emotion regulation strategy as effectively as individuals without BPD (e.g. Lang et al., 2012; 
Marissen, Meuleman \& Franken, 2010; Ruocco, Medaglia, Ayaz \& Chute, 2010), they may need to implement that skill to a greater degree to achieve the same result as an individual without BPD. That is, although both HCs and individuals with BPD need to acquire and strengthen emotion regulation skills for them to be effective, individuals with BPD may need to strengthen them more than HCs.

In keeping with this proposal of skill strengthening deficits in BPD, findings from other clinical populations indicate that skill strengthening can be impaired. Examples from other behaviourally oriented therapies, such as exposure therapy, are informative. Exposure therapy, also called systematic desensitization, is an established treatment for many disorders including social anxiety disorder, specific phobia, posttraumatic stress disorder (PTSD), and body dysmorphic disorder (Foa, 2011; Coles \& Heimberg, 2000; Kaplan \& Tolin, 2011; McKay et al., 1997). It consists of exposing an individual to a distressing stimulus that is functionally related to the disorder in a safe, and controlled manner. Through automatic processes of implicit learning (i.e. extinction), repeated exposure to the distressing stimulus extinguishes the distress response. Like emotion regulation skills training, exposure to the feared stimuli must be repeated for the new responses to be strengthened.

Both theory and research indicate that progressive, hierarchical, exposure is necessary, as high levels of sympathetic arousal can hinder treatment (Lader \& Wing, 1966; De Jong \& Boersma, 2010). Indeed, unbearable emotional intensity is the predominant reason suggested for the failure of improvements to occur (Rodriguez \& Craske, 1993). Within the two-factor model, high emotional intensity may be one factor that impedes the strengthening of new responses that are developed in exposure therapy. For example, in an undergraduate sample, Jackson (1974) reported that the more intense the response evoked by a stimulus, the slower the rate of change in 
response to repetitions of that stimulus. Likewise, Eckman and Shean (1997) found that, compared to low socially anxious individuals, high socially anxious individuals showed smaller improvements in both subjective measures (i.e. self-report) and physiological measures (i.e. heart rate and sweat activity) of anxiety across repeated exposure to an anxiety provoking situation. Similar results have been found among individuals with PTSD (van Minnen \& Hagenaars, 2002). Therefore, when treatment occurs in the context of high emotional intensity, strengthening of new responses can be delayed.

In sum, research indicates that 1) individuals with BPD show heightened emotional intensity and 2) heightened emotional intensity can delay improvement following behavioural treatments for other disorders. Consequently, these findings suggest that individuals with BPD may too have delayed improvements, or, in other words, deficits in skill strengthening. Furthermore, research suggests that these deficits may vary by emotion regulation skill (i.e., deficits may be greater in some skills versus others). For example, studies have found that individuals with BPD are high in experiential avoidance, which is the refusal or reluctance of an individual to engage in specific internal and private experiences which include, but are not limited to, thoughts, emotions, bodily sensations and memories (Hayes, Wilson, Gifford, Follette \& Strosahl, 1996.) Indeed, heightened experiential avoidance has been identified as one of the features that distinguishes personality disorders from non-pathological personality functioning; and within psychiatric inpatients, avoidant coping has been shown to be higher among individuals with BPD than in those with other personality disorders (Bijttebier \& Vertommen, 1999). Given that experiential avoidance is the refusal or reluctance to attend to internal experiences, and mindful awareness requires individuals to direct attention to those same internal 
experiences, it seems likely that individuals with BPD would display deficits strengthening mindful awareness compared to HCs.

Relatedly, many of the dysfunctional behaviours (e.g. suicidal behaviour, substance abuse) that are commonly observed in BPD can be conceptualized as experientially avoidant. For example, Chapman, Gratz and Brown (2006) proposed a model of non-suicidal self-injury (NSSI) in individuals with BPD based exclusively on experiential avoidance. The model posits that individuals with BPD engage in NSSI as a means of escaping, or avoiding, unwanted emotional experiences. Consequently, these maladaptive behaviours are maintained via negative reinforcement. As a disengagement skill, distraction too is negatively reinforced. However, given that these dysfunctional behaviours are already part of the individual's behavioural repertoire, it may be more difficult for individuals with BPD to incorporate adaptive distraction as it would need to displace and compete with pre-existing, and strongly reinforced behaviours.

Thus, both theory and empirical research indicate that individuals with BPD may have deficits in emotion regulation skill strengthening, and that these deficits may be larger for specific emotion regulation skills, including mindful awareness and distraction. To date, however, no study has examined the rate at which improvements in emotion regulation skills occur among individuals with BPD as compared to healthy individuals.

\section{The present study}

The present study used an experimental paradigm to examine whether or not individuals with BPD show a deficit in skill strengthening as compared to HCs. Data were collected as part of a larger parent study that investigated baseline intensity and emotion regulation strategy effectiveness in individuals with BPD as compared to HCs (Kuo, Fitzpatrick, Metcalfe \& McMain, 2013; paper presented at the annual convention of the Association for Behavioral and 
Cognitive Therapies). Twenty-five individuals with BPD and $30 \mathrm{HCs}$ were instructed to repeatedly implement two emotion regulation strategies (i.e., mindful awareness and distraction) in response to BPD-relevant stimuli across multiple trials. In order to address the discrepancy across methodologies regarding the types of measures used (i.e., self-report vs. psychophysiological), we employed a comprehensive assessment approach. Throughout the task, both self-reported negativity and positivity, and physiological indices of emotion (i.e., heart rate and skin conductance response) were collected. The following were the hypothesized outcomes: Hypothesis 1: Individuals with BPD and HCs will exhibit skill strengthening of both mindful awareness and distraction over time.

Skill strengthening would be indicated by a decrease in self-reported and physiological indices of emotional intensity across trials as compared to a control condition in which participants were instructed to react naturally (i.e., absence of a regulation instruction)

Hypothesis 2: Individuals with BPD will exhibit a deficit in skill strengthening of both mindful awareness and distraction over time relative to the HCs.

A deficit in skill strengthening would be indicated by a greater decrease (i.e. a steeper slope) in self-reported and physiological measures of emotional intensity for HCs than for individuals with BPD.

Exploratory analysis: The second goal of the study was exploratory in nature and investigated the relationship between emotion regulation strategy (i.e., distraction and mindful awareness), group (i.e., BPD or HC), and skill strengthening. More specifically, to determine whether or not hypothesized skill strengthening deficits were broad (i.e., applied to all emotion regulation strategies) or specific (i.e., applied to only one type of strategy), we explored whether there was an interaction between rate of skill strengthening and emotion regulation strategy; rate of skill 
strengthening and group (e.g. BPD or HC); or between both group and emotion regulation strategy.

\section{Method}

\section{Participants}

Individuals with BPD $(n=25)$ between the ages of 18 and 60 were recruited from the BPD Clinic at the Centre for Addiction and Mental Health (CAMH). The majority of individuals with BPD $(n=23)$ were recruited from an on-going clinical trial examining DBT group skills training as a stand-alone treatment. Due to the ethics of withholding treatment from a highly suicidal population, all participants were permitted to continue treatment as usual. Because an individual must be 18 years of age or older for a personality disorder diagnosis to be given, individuals under the age of 18 were ineligible for the study (American Psychiatric Association, 2013). The majority of participants with BPD were taking psychoactive medications at the time of the laboratory task, including: antidepressants (68\%); mood stabilizers (56\%); benzodiazepines (40\%); sedatives (14\%); and stimulants (4\%). In addition, consistent with other BPD studies, individuals with any DSM-IV diagnosable psychotic disorder, bipolar disorder, or dementia, or who show evidence of an organic brain syndrome or mental retardation were excluded. Current and past diagnoses for individuals with BPD are presented in Table 1.

Thirty HCs were recruited from the community by means of flyers, internet postings, and word-of-mouth relay of information. HCs who met criteria for a current axis-I diagnosis and/or who met four or more of the DSM-IV TR criteria for BPD were excluded from the study. As well, HCs who met item "(5) recurrent suicidal behaviour, gestures, or threats, or self-mutilating behavior" (American Psychiatric Association, 2013, p. 663) were ineligible for participation in 
the study in order to ensure diagnostic distinction between groups. Demographic data for both groups are presented in Table 2.

Insert Table 1 here

Insert Table 2 here

\section{Screening and Assessment Procedures}

Interested individuals were contacted by phone to complete a brief phone-screening to assess for exclusion criteria. Individuals who did not endorse any of the exclusion criteria were scheduled for a formal diagnostic interview. Individuals with BPD were assessed by a Masters level assessor working at CAMH to ensure criteria for BPD were met at the time of the study and to determine which, if any, axis-I diagnoses were met at the time of the study. HCs were assessed by a trained Bachelors level assessor who was under the supervision of a licensed Clinical Psychologist. Research shows that with appropriate supervision, there are no differences between neophyte and experienced interviewers on inter-rater reliability or diagnostic accuracy when administering the SCID-I (Ventura, Liberman, Green, Shaner \& Mintz, 1998). Because the assessments of individuals with BPD and those recruited as HCs were conducted by two different assessors, another 10 individuals between the ages of 18 and 60 years of age were recruited from the community by means of flyers and online postings for the purposes of establishing inter-rater reliability. Reliability assessments were conducted no more than 5 days apart. Inter-rater reliability for the SCID-I and IPDE-BPD ranged from $\kappa=.74-1.0$. 


\section{Measures}

Screening and descriptive measures. All participants were administered the Structured Clinical Interview for DSM-IV Axis-I Diagnoses (SCID-I) in order to determine DSM-IV axis-I diagnoses. The SCID-I has excellent psychometric properties, including high inter-rater reliability with Kappa values ranging from .60 to .83 for individual axis-I diagnoses of mood, anxiety, psychotic, and eating disorders (Lobbestael, Leurgans, \& Arntz, 2011; Ventura, Liberman, Green, Shaner, \& Mintz, 1998). Demographic information were obtained using the overview section of the SCID-I which includes questions about age, marital status, education, and occupational history.

All participants were administered the BPD section of the International Personality Disorders Examination (IPDE) to determine the presence of BPD, as well as to obtain a dimensional score of endorsement of BPD criteria. The IPDE uses specific questions to assess patterns of behaviour both in the past 5 years, and before 25 years of age. The IPDE is well validated and has been shown to have good inter-rater reliability and diagnostic accuracy $(\kappa=$ .73; Loranger, et al., 1994; Mann, et al., 1999).

\section{Measures of emotional intensity.}

Self-report. A 9-point Likert scale was used to assess participants' emotional intensity via self-report. For the purposes of this study, emotion was conceptualized as a flexible state response to an external stimulus (Gross, 1998). All participants were asked to rate how negative they feel (with "1" being "not negative at all" and "9" being "very negative"), and how positive they feel (with "1" being "not positive at all" and "9" being "very positive") after each image was presented in the experimental paradigm. 
Heart rate $(\boldsymbol{H R})$. Heart rate was measured as an index of physiological arousal (Fowles, 1980; Appelhans \& Luecken, 2006) throughout the experimental paradigm. Electrocardiography (ECG) was used to measure the rate and regularity of heartbeats. ECG was collected using a BIOPAC 5-channel acquisition system (BIOPAC Systems Inc., Model MP150, Goleta, CA). Two 35-mm electrodes with electrode gel (BIOPAC Systems Inc., Model EL503) were placedone on anterior of the left wrist, and the other below the right clavicle (Kusumoto, 2009). A bioimpedance module was used for ground referencing. An electrocardiogram was produced using AcqKnowledge 4.1 software. MindWare Technologies HRV 3.0.16 program was used to process collected ECG data.

Skin conductance level (SCL). Skin conductance level (SCL) was used as an index of sympathetic responding. SCL was collected using a BIOPAC 5-channel acquisition system (BIOPAC Systems Inc., Model MP150, Goleta, CA) throughout the experimental paradigm. Two electrodes with gel (BIOPAC Systems Inc., Model EL507) were placed on the medial phalanges of the index and middle fingers of the nondominant hand, in accordance with established standards (Fowles, et al., 1981). MindWare Technologies EDA 3.0.15 program was used to process collected SCR data. Data will be digitized at 1,000 samples per second using high- $(.05$ $\mathrm{Hz})$ and low- $(35 \mathrm{~Hz})$ pass filters. Skin conductance level was calculated as the difference between skin conductance level during each trial and the mean skin conductance level during presentation of the 2 second fixation cross prior to each trial.

Emotionally evocative images. Ninety-six images were chosen from the International Affective Picture System (IAPS) (Lang, Bradley, \& Cuthbert, 2008). The IAPS is an inventory of images that have each been rated for normative responses on both arousal (rated from 1 to 9 , with 1 being low arousal and 9 being high arousal) and valence (rated from 1 to 9 , with 1 being low 
pleasure and 9 being high pleasure) (Lang, Bradley, \& Cuthbert, 2008). Given Limberg and colleagues' (2011) findings that individuals with BPD display heightened intensity in response to disorder-specific stimuli only, of the 96 images chosen, 72 were negative and BPD-relevant and 24 were neutral. A previous study that identified images and themes that were particularly relevant for individuals with BPD (Sloan et al., 2010) informed the selection of the 72 BPD relevant images. These themes included women being attacked, distressed individuals, substance use, and aggressors. The 72 images were divided into three sets of 24 images (A, B, and C), one set for each condition. The three sets had equivalent arousal and valence ratings ( $p=.29$, and .31 , respectively).

To control for potential non-random individual responses to the negative images, each set of 24 negative images (A, B, and $\mathrm{C}$ ) was assigned to each of the three conditions described below (react, distract, and notice). Furthermore, to control for order effects (i.e. whether a participant began with a notice block or a distract block), the order of the blocks was counterbalanced. Thus there were six versions ( 3 image sets by 2 block orders) of the final experiment.

\section{Laboratory Procedure}

Upon arrival at the laboratory, participants were given a description of the study and were then asked to provide informed consent. Subsequently, electrodes were placed on the participants as described above. Participants then completed a 10-minute baseline period during which they were asked to sit still and quietly (data presented at the 2013 annual convention of the Association for Behavioral and Cognitive Therapies).

Emotion regulation paradigm. 
Training and practice phase. Immediately following the baseline period, participants began the practice phase of the study. Participants viewed images that were not used in the experiment phase and were instructed to respond to the images in one of three ways. First, when the "React" (i.e. control /non-regulation condition) instruction appeared on the screen, participants were instructed to react to the image as "they normally or naturally would." Second, when the "Distract" (i.e., distraction condition) instruction appeared on the screen, participants were instructed to "try and change your emotional response by thinking of something neutral while still attending to the distressing stimulus." Third, when the "Notice" (i.e. mindful awareness condition) instruction appeared on the screen, participants were instructed to "attend to and notice the present experience without trying to change it."

The training/practice phase was divided into two sections. In the first section, participants were taught to distract, and then practiced between distracting (in response to negative images only) and reacting (in response to negative or neutral images). The training phase was guided by an experimenter, and consisted of five self-paced trials. Following five self-paced training trials, participants completed ten non-self-paced practice trials where they were again be asked to either distract or react to the images that appeared. The timing in the practice session was the same as the timing in the experiment. The second training/practice phase followed the same format as the first. However, instead of alternating between distract and react conditions, participants were asked to either notice (in response to negative images only) or react (in response to negative or neutral images).

Experimental phase. There were three types of trials, one for each instruction type (i.e., react, distract, notice). In the task, participants first saw a fixation cross for 2 seconds. Next, the instruction (i.e., "react", "distract" or "notice") was shown for 2 seconds. After the instruction a 
negative or a neutral image was shown for 10 seconds during which the participant implemented one of the two regulation strategies (i.e., distraction or mindful awareness) or the non-regulation control strategy (i.e., reaction). Following each image participants provided an experiential rating of their emotion response (negativity 1-9 scale $(M=4.12, S D=2.67)$; positivity $1-9$ scale $(M=2.95, S D=2.09))$. The time-frame of each trial is shown in Figure 1.

The entire task consisted of four blocks. Each block contained 24 images. Of these 24 images, 6 were neutral react trials, 6 were negative react trials, and 12 were negative notice trials or negative distract trials. Participants were not asked to alternate between "distract" and "notice" strategies in a single block (i.e., blocks contained "distract" and "react", or ""notice" and "react" conditions only). To avoid confusion that may have resulted from attempting to employ an emotion regulation strategy when no emotional response was present, -participants were not asked to use the "distract" or "notice" strategies on neutral trials. The order of images and of regulation instruction was counterbalanced across participants. Within each block, whether an individual was responding to the emotion regulation instruction or the "react" instruction varied randomly across trials, while ensuring that no instruction was presented in more than two consecutive trials. Each image was presented only once. As a manipulation check, at the mid-point and the end of the experiment participants were asked to indicate how often they followed the "distract" and "notice" instructions. Although heavily based upon the affective science literature (e.g., Goldin, McRae, Ramel \& Gross, 2008; Gross \& John, 2003), the laboratory procedure was developed for the parent study.

\section{Data Analytic Strategy}

Hierarchical linear modeling (HLM; Raudenbush, 1993; Raudenbush \& Bryk, 2003) was used to analyze the data. HLM is an ideal strategy to address the hypotheses because it allows for 
the simultaneous analysis of relationships across multiple levels, i.e., data that are nested (Woltman, Feldstain, MacKay \& Rocchi, 2012). Additionally, HLM combines the advantages of analysis of variance (ANOVA) and multiple regression in that it allows the use of both discrete (e.g., group) and continuous (e.g., time) variables (Raudenbush \& Bryk, 2003). Furthermore, unlike multiple regression, HLM does not require variables to be independent of one another, thus multiple related dependent variables can be analyzed (Willms, 1999). Consequently, using HLM, individual change over time on self-report and physiological measures by group can be determined.

HLM is well-suited to the present study's aims. First, the focus of this study's hypotheses was on time, and, more specifically, the trajectory of skill strengthening over time. However, unlike many analyses, the specific changes between any two time points were not of interest. Instead, the focus was on the average rate of change across the laboratory task. HLM was chosen because it addresses this focus exactly and allows time to be analyzed as a continuous variable, unlike generalized estimating equations or mixed model ANOVAs (Feingold, 2009; Hardin \& Hilbe, 2002).

Second, the present data set is nested - a configuration for which HLM was specifically developed. The dataset is composed of two levels of data. The first level examines intraindividual factors and, specifically, two predictors: condition (i.e., distraction, mindful awareness, and reaction) and time. The second level of modelling examines inter-individual differences due to diagnostic status (i.e., HCs vs. individuals with BPD). All three factorscondition, time, and diagnostic status_ - are assessed as predictors of self-reported negativity and positivity, HR, and SCL. 
Third, HLM does not require as many assumptions to be met as other statistical analyses; it is able to model datasets that have discrepant group sample sizes, as is the case in the present study (i.e., 30 HCs; 25 individuals with BPD; Raudenbush, 2004).

Fourth, given that the considerable length of the laboratory task conducted (i.e., 96 trials) amplified the challenges commonly posed by the collection of physiological data via electrodes (e.g., participant fidgeting, sweating, etc.), several data points are absent. HLM is able to accommodate this via listwise deletion at level 1 of the model. Listwise deletion has been shown to be a reliable method of handling missing data in multilevel models, and performs better than computerized imputation (Medhanie, 2013).

Finally, HLM is versatile in that it allows for multiple covariance structures to be tested and fitted to a given dataset. Two common covariance structures are compound symmetry, and autoregressive (Littell, Pendergast \& Natarajan, 2000). The former assumes that variance is homogeneous and all data points from a given participant are equally correlated. The latter also assumes homogenous variance, but assumes that the correlation between data points for a given participant decreases as the time between those points increases. Given that the present study used a blocked design (e.g., distraction and reaction in blocks 1 and 3, and mindful awareness and reaction in block 2 and 4), neither of these structures was appropriate. Consequently an unstructured covariance structure, which allows for statistical independence of each data point, was used.

Primary analysis. Twelve sets of HLM analyses (3 pair-wise comparisons X 4 outcome variables) were conducted to allow for planned pair-wise contrasts between each of the conditions (i.e., distraction vs. reaction; mindful awareness vs. reaction; and mindful awareness vs. distraction) and for each outcome variable (i.e., HR, SCL, and self-reported negativity and 
positivity). First, contrasts comparing each emotion regulation strategy condition to the control condition (i.e., distraction vs. reaction; and mindful awareness vs. reaction) were conducted for each of the four outcome variables. These contrasts assessed: 1) whether any changes that occurred during implementation of an emotion regulation strategy were above and beyond those predicted by the passage of time; and 2) whether individuals with BPD showed a deficit in skills strengthening. Second, a contrast comparing the two emotion regulation strategies (i.e., distraction vs. mindful awareness) was conducted for each outcome variable to assess whether group differences in rate of skill strengthening were modulated by emotion regulation skill type. For each of the 12 analyses, diagnostic status (BPD or HC) was entered as the between-subjects factor, and condition (i.e., distraction, mindful awareness, or reaction) and trial number (the time variable) were entered as within-subjects factors.

Individual models were built for each of the 12 sets of analyses. For each set, models were built first by entering only the main effects of condition, diagnostic status, and time. In the second step of model building, all three main effects were entered, as well as the three two-way interaction terms: condition $\mathrm{X}$ diagnostic status; emotion regulation strategy $\mathrm{X}$ time; and diagnostic status $\mathrm{X}$ time. In the third step, all three main effects and all three two-way interaction terms were entered, as well as the three-way interaction of condition $\mathrm{X}$ diagnostic status $\mathrm{X}$ time. The final model was built by including the significant terms from the model with the most complex significant term, as well as all the terms from the previous step. For example, if in the second step a two-way interaction and two main-effects were significant, and in the third step, the three-way interaction was not significant but all three two-way interactions were, the final model would include the significant two-way interaction from the second step and all three main- 
effects from the second step. As all hypotheses addressed are related to changes across time, any significant results were further investigated using simple slopes tests.

\section{Hypothesis 1 and 2: Skill strengthening among individuals with BPD and HCs.}

Hypothesis 1. Individuals with BPD and HCs would both show skill strengthening as indicated by a decrease in self-reported measures of negative emotional reactivity and physiological (i.e., HR, SCL) measures, and an increase in self-reported positivity across trials in the two emotion regulation conditions relative to the reaction condition. This hypothesis was tested by examining the condition $\mathrm{X}$ time interaction in two contrasts-distraction vs. reaction, and mindful awareness vs. reaction.

Hypothesis 2. Individuals with BPD would show a deficit in skill strengthening relative to HCs as indicated by a slower rate of decrease in self-reported negativity, HR, and SCL, and a slower rate of increase in self-reported positivity across trials. This hypothesis was tested by examining the condition $\mathrm{X}$ diagnostic status $\mathrm{X}$ time interaction in two contrasts-distraction vs. reaction, and mindful awareness vs. reaction.

Exploratory analysis: Examining the relationship between emotion regulation strategy and group, and skill strengthening.

The exploratory analyses investigated if rate of skill strengthening differed based on emotion regulation strategy, and if so, whether the difference between the rate of skill strengthening in emotion regulation strategy was moderated by diagnostic status, as measured by changes in physiological (i.e. HR, SCL) and self-report (i.e., self-reported negativity and positivity) indices. 
The interactions of these relationships were explored by examining the condition $\mathrm{X}$ diagnostic status $\mathrm{X}$ time interaction term in the distraction vs. mindful awareness contrast. A significant three-way interaction was delineated using simple slopes tests.

\section{Results}

The final models for the distraction vs. reaction, mindful awareness vs. reaction, and distraction vs. mindful awareness contrasts are presented in tables 3, 4, and 5, respectively. Additionally table 6 lists the means and standard deviations for the first and last trial of each condition by group for each outcome measure.

Insert Table 3 here

Insert Table 4 here

Insert Table 5 here

Hypothesis 1: Individuals with BPD and HCs would both show skill strengthening

Distraction vs. Reaction. Results partially supported Hypothesis 1 with a significant condition $\mathrm{X}$ time interaction for self-reported negativity in the distraction vs. reaction contrast $(F(1,2400)$ $=8.96, p=.002$ ) such that individuals in both groups exhibited increased negativity over time when reacting $(t(97.2)=3.72, p=.0003 ; \beta=.009, S E=.002)$, but not when distracting $(t(112)=$ 
$.38, p=.701)$. In contrast, the interaction of condition $\mathrm{X}$ time was not significant for $\mathrm{HR}, \mathrm{SCL}$, or self-reported positivity (see Table 3).

Mindful awareness vs. Reaction. The interaction of condition X time was not significant for any of the four outcome variables (see Table 4).

Hypothesis 2: Individuals with BPD would show a deficit in skill strengthening relative to HCs

Distraction vs. Reaction. The interaction of condition X diagnostic status X time was not significant for any of the four outcome variables (see Table 3).

Mindful awareness vs. Reaction. The interaction of condition X diagnostic status X time was not significant for any of the four outcome variables (see Table 4).

\section{Exploratory Analysis}

Distraction vs. Mindful awareness. Results partially supported our hypothesis that emotion regulation skill strengthening would be moderated by diagnostic status and emotion regulation strategy, with a significant interaction of condition $\mathrm{X}$ diagnostic status $\mathrm{X}$ time for $\mathrm{HR}(F(1$, $2450)=7.46, p=.006$; see Table 5). Simple slopes tests to unpack the HR interactions showed that HR significantly decreased over time for the HCs when employing distraction $(t(87)=-2.44$, $p=.018 ; \beta=-.02, S E=.008)$, but not when employing mindful awareness $(t(87.6)=0.22, p=$ .83), suggesting that HCs show skill strengthening of the distraction strategy, but not the mindful awareness strategy. In contrast, HR significantly decreased over time for individuals with BPD when employing mindful awareness $(t(86.3)=-2.59, p=.01 ; \beta=-.023, S E=.009)$ but not for distraction $(t(89.7)=-1.12, p=.26$. Consistent with these findings, planned contrasts showed that HCs had significantly greater HR overall when implementing mindful awareness compared to HCs implementing distraction $(t(86.9)=2.06, p=.042 ; \beta=.025, S E=.012)$, and individuals with BPD implementing mindful awareness $(t(2450)=2.55, p=.011 ; \beta=.022, S E=.009)$. 
Insert Table 6 here

\section{Discussion}

This study was the first laboratory investigation to compare emotion regulation skill strengthening among individuals with BPD and HCs. Results indicate that both individuals with BPD and HCs evidence skill strengthening when instructed to engage specific emotion regulation strategies multiple times, and that the rate of skill strengthening varies by emotion regulation strategy and by diagnostic status.

\section{Hypothesis 1: General Skill Strengthening Across Groups}

We found partial support for the strengthening of emotion regulation strategies when individuals are instructed to implement those strategies multiple times. When distracting, both individuals with BPD and HCs reported decreased negativity over time compared to when they were instructed to react naturally. Interestingly, this pattern of results did not hold true for the mindful awareness versus reaction contrast. For both emotion regulation conditions, there was no evidence of skill strengthening as indicated by HR, SCL, or self-reported positivity.

Although potentially counterintuitive, there are several possible explanations for the different outcomes between distraction and mindful awareness. First, it may be that participants found distraction to be a relatively easier strategy to implement than mindful awareness, thus decreasing the time needed to strengthen the skill. Indeed, while distraction consists of thinking of something emotionally neutral that is unrelated to the stimulus, mindful awareness consists of multiple components, including attending to the stimulus while simultaneously observing emotional, physiological, and cognitive responses to that stimulus (Bishop et al., 2004). It may 
be, then, that strengthening or mastery of mindful awareness takes more time than mastery of distraction. Thus, potentially more time is needed to see differences between mindful awareness and natural reaction over time, than to see differences between distraction and natural reaction.

In addition to the relative complexity of distraction and mindful awareness, theoretical models of emotion may also explain the discrepancy between the two conditions. The process model of emotion regulation posits that engagement strategies (i.e., mindful awareness) work more slowly than disengagement strategies (i.e., distraction) (Gross, 2002). Thus, it may be that the amount of time participants were instructed to implement mindful awareness (i.e., 10 seconds) was not sufficient for mindful awareness to be fully deployed. Speaking to this, the only study to date that has examined the relative speed with which engagement and disengagement strategies take effect found that engagement strategies take effect more slowly (i.e., Thiruchselvam, Blechert, Sheppes, Rydstrom \& Gross, 2011). However, the study used a nonclinical sample, and did not examine mindful awareness specifically. Thus, further research that examines the speed with which these commonly taught emotion regulation skills take effect in clinical populations, including individuals with BPD, is warranted.

Notably, skill strengthening in the distraction condition was only evidenced by a decrease in self-reported negativity, and not in changes across the other three variables (i.e., HR, SCL, or self-reported positivity). These results are consistent with research from affective science which indicates that emotional responses consist of several different components which are loosely coupled (e.g., physiological, experiential etc.; see Mauss \& Robinson, 2009, for a review). More specifically, although it is commonly assumed that these components work synergistically, work from affective science suggests that these components may reflect independent emotion processes, and consequently change in one component may be independent of change in another 
(Ingjaldsson, Laberg \& Thayer, 2003; Kuo \& Linehan, 2009). Thus, a decrease in self-reported negativity and the absence of changes in other outcome variables are not necessarily contradictory findings. Early theoretical work by Hodgson and Rachman (1974) posits that synchrony in emotional responding is a function of many disparate components, including intensity of the emotional response, and the level of demand (i.e., how demanding laboratory instructions are). Furthermore, Hodgson and Rachman posit that therapeutic interventions that require individuals to attend to negatively evocative stimuli are more like to result in desynchrony. Thus, given that the present study required continuous visual focus on negative stimuli, and the implementation of specific laboratory instructions, it is unsurprising that results vary across outcome measures. More recent research from affective science, too, supports the decoupling of emotion process. A 2005 study by Mauss and colleagues found that changes in self-reported negative affect in response to a negative stimulus were negatively correlated with changes in SCL, but not correlated with changes in cardiovascular measures. Despite the fact that the study did not use an emotion regulation strategy manipulation, the findings suggest that emotion processes in general are loosely coupled. Indeed, although Mauss and colleagues (2005) only examined the interrelatedness of physiological and experiential measures during emotion reactivity, these results may also apply to emotion regulation. Speaking to the applicability of these findings to regulation, one of the few studies examining the coherence between physiological and subjective measures during implementation of an emotion regulation strategy found that the use of a disengagement strategy when viewing a disgust-eliciting film decreased heart rate, while increasing electrodermal responding (i.e., SCL; Gross \& Levenson, 1993).

\section{Hypothesis 2: Delayed Skill Strengthening Among Individuals with BPD}


Results from this study did not support the second hypothesis that individuals with BPD would show slower improvements in both emotion regulation strategies than HCs. Instead, no differences were found between individuals with BPD and HCs on skill strengthening for either emotion regulation strategy.

There are several potential explanations for this counter-intuitive finding. First, it is possible that the stimuli used were not of sufficient intensity to provoke heightened emotional response in individuals with BPD relative to $\mathrm{HCs}$ and thus, regulation of these responses was not sufficiently "challenging." Although the present study did select images rated by experts as BPD-relevant from a standardized testing bank, research suggests that heightened emotional response may be particularly evident among individuals with BPD when dynamic (i.e., auditory or visual) stimuli are used (Kuo, Fitzpatrick, Neausciu \& McDonald, 2013; Rosenthal et al., 2011). Furthermore, some individuals with BPD, but no HCs, reported to the study experimenter that their strongest emotional responses were provoked by neutral images because these recalled memories from past traumas. This anecdotal evidence suggests that individuals with BPD were more likely to have responses that were incongruent with expected responses. Further compounding this effect, all neutral images were in the react condition. Thus, it is possible that if more evocative stimuli were used (and if neutral stimuli were removed from the react condition or added to the other conditions) that individuals with BPD would experience heightened emotional responding, and potentially a slower rate of skill strengthening.

Alternatively, it is also possible that our "control" condition did not effectively function as a true "control." The intent of the "react" condition was to measure participants' natural reactions to the stimuli as opposed to intentional implementation of the two emotion regulation strategies of interest. Consequently, in the react condition, all participants were instructed to 
"react as you normally or naturally would." Although this served as an appropriate instruction to compare volitional versus avolitional emotion regulation processes, it is unclear what each participant did when reacting naturally. It is possible that participants' natural reaction was, in fact, to use an engagement (i.e., mindful awareness) or disengagement (i.e. distraction) strategy, thereby muddying the distinction between the emotion regulation conditions, and the reaction condition. In support of this hypothesis, multiple studies have shown that individuals with BPD are highly experientially avoidant (Bijttebier \& Vertommen, 1999; Chapman, Specht \& Cellucci, 2005; Kruedelbach, McCormick, Schulz \& Grueneich, 1993; Welch, Linehan, Sylvers, Chittams \& Rizvi, 2008). Disengagement strategies, like distraction, have been likened to experiential avoidance because they are withdrawal strategies which blunt the processing of the affectively evocative stimulus (Wolgast, Lundh \& Viborg, 2013). It is likely, then, that individuals with BPD were engaging in experiential avoidance during the react condition. Compounding the likelihood that individuals with BPD may have been implementing an emotion regulation skill during the "react" condition, participants in the study were permitted to be receiving non-DBT treatment at the time of the study. The amount and type of treatment varied by participant, and ranged from psychotherapeutic intervention to psychiatric management. The current use of psychotherapeutic interventions may have increased the likelihood that individuals would implement an engagement or disengagement strategy during the "react" condition. Thus, a failure to find differences may be due to the absence of a "true control" condition in which individuals refrained from any attempt at emotion regulation.

Finally, it is possible that rather than being an artifact of study design, the results found here are an accurate reflection of rate of skill strengthening among individuals with BPD. That is, it is possible that, contrary to the hypothesis, individuals with BPD do not have a deficit in 
emotion regulation skill strengthening in a controlled context. This result may appear to be in conflict with clinical observations and empirical studies of emotional responding in individuals with BPD. However, the present study examined the process of skill strengthening and not the final outcome. That is, it examined the rate of skill strengthening (i.e., change over time), and not the amount of time required to reach a given level of emotional arousal. Thus, though these results suggest that individuals with BPD can strengthen emotion regulation strategies at the same rate as HCs, they do not necessarily indicate that individuals with BPD and HCs will "land" at the same level of emotional intensity after implementation of an emotion regulation strategy. Indeed, data from the present study support previous investigations indicating that individuals with BPD typically exhibit higher negative baseline emotional intensity than HCs (e.g., individuals with BPD exhibited significantly higher resting heart rate $(M=79.08, S E=$ 2.58) than HCs $(M=71.42, S E=2.03), p<.01)$. Thus, even if individuals with BPD can effectively decrease this intensity through skill strengthening, it is likely that this group does not experience this strengthening as particularly effective, if, ultimately, they are still experiencing high levels of emotional intensity even after strategy implementation.

This finding provides partial support for leading theories of BPD (i.e., Linehan, 1993; Selby, Anestis, Bender \& Joiner, 2009) which emphasize the role of increased emotional intensity in BPD, and specifically posit that individuals with BPD have difficulties with both emotion regulation and emotional intensity. Findings from the present study refine this position, and further indicate that rather than a deficit in skill strengthening, individuals with BPD simply have more emotion to regulate, and thus need to strengthen emotion regulation skills at an even greater rate (or perhaps, simply need more time) to achieve the same result as HCs. However, to understand emotion regulation skill strengthening in the context of Linehan's (1993) model more 
fully, future studies should consider the role of the invalidating environment as well as current emotional responding.

\section{Exploratory Analysis: Does Rate of Skill Strengthening in Each Group Vary by Emotion}

\section{Regulation Strategy?}

Our results suggest that the rate of skill strengthening in each group does vary by emotion regulation strategy. Specifically, HCs showed strengthening of the distraction emotion regulation skill over time as measured by changes in HR, while individuals with BPD did not exhibit any change (either a strengthening or a weakening) of the distraction emotion regulation skill over time. In contrast, individuals with BPD showed a strengthening of mindful awareness over time as measured by decreases in HR, while HCs did not show any change (either a strengthening or a weakening) of mindful awareness over time.

Once again, this pattern of findings might be explained by the process model of emotion regulation (Gross, 2002). This model states that different emotion regulation strategies are adaptive at different times, and the adaptiveness of an emotion regulation strategy is heavily contingent on the level of emotional intensity experienced by the individual. When emotional intensity is low, engagement strategies (e.g., mindful awareness) are optimal as they permit information processing and learning, although they take effect more slowly. In contrast, disengagement strategies (e.g., distraction) are optimal when emotional intensity is high as they regulate emotions quickly but inhibit information processing and learning. Put simply, adaptive emotion regulation requires that individuals flexibly match emotion regulation strategies to their emotional intensity level. As indicated above, research and data from the present study indicate that individuals with BPD have a higher baseline level of emotional intensity, and have emotional responses that are correspondingly greater in intensity than HCs (Conklin, Bradley \& 
Westen, 2006; Glenn \& Klonsky, 2009; Levine, Marziali \& Hood, 1997; Yen, Zlotnick \& Costello, 2002). Thus, it may be that the high level of emotional intensity in day-to-day living leads individuals with BPD to (appropriately) use disengagement strategies (i.e., distraction) much of the time. Indeed, this conclusion is supported by evidence of high experiential avoidance among individuals with BPD (discussed above). In contrast, HCs have comparatively lower emotional intensity and may employ engagement strategies more regularly than individuals with BPD. Thus, the present results may reflect a "ceiling effect" for skill strengthening that varies based on the frequency with which each emotion regulation strategy is used in an individual's life. In the aggregate, then, it may be that individuals with BPD show no change in distraction over time because disengagement strategies are frequently used in this population, i.e., the skill is already "strengthened." Instead, perhaps individuals with BPD evidence improvement in mindful awareness due to less in vivo practice. In contrast, it is possible that HCs show improvement in distraction because they use disengagement strategies relatively less frequently than engagement strategies.

Our finding that the BPD group exhibited strengthening of mindful awareness has significant clinical implications. Specifically, these results indicate that, despite typically deploying disengagement strategies, individuals with BPD are able to effectively learn, implement, and strengthen complex engagement strategies, even within a short period of time (i.e., 24 ten second trials). This finding is particularly noteworthy given that mindful awareness is a core skill involved in several psychotherapies (e.g., Mindfulness-Based Stress Reduction; Acceptance and Commitment Therapy), including DBT. To date, treatment for BPD has been time intensive, with standard treatments often taking 12 months (Gunderson, 2011). Thus, that 
improvements in emotion regulation strategy implementation were evident in a short, single strengthening period further bolsters the significance of these findings.

\section{Clinical Implications}

More targeted treatments. Our findings provide implications for ways in which treatments for BPD may be further refined. First it may be that treatment needs to increase focus on building skills that interrupt emotional avoidance. In the present study, mindful awareness may have been strengthened in individuals with BPD because it directly competed with emotional avoidance and essentially "forced" engagement with emotionally arousing stimuli. Indeed, given our speculation that individuals with BPD have already "strengthened" disengagement strategies, it may be that treatments should focus predominantly on strengthening engagement strategies.

Use of biofeedback. Although both groups of participants showed improvements in emotion regulation skills as measured by HR, these improvements were small. It is possible, then, that despite these improvements being measureable, they were not necessarily noticeable to the participants themselves. Thus, biofeedback tools may provide participants gain awareness that improvements are occurring, even if those improvements are not yet perceptible to them, and thereby provide reinforcement for emotion regulation skills training. For example, individuals could be shown readings of their own HR during emotion regulation skills training. In addition to providing reinforcement that the effort expended is producing results, using biofeedback may help individuals become more aware of the changes in physiological sensations that accompany successful emotion regulation.

\section{Limitations of the Study}

Findings from this study should be considered in the context of its limitations. 
First, although more ecologically valid, the inclusion of both male and female identified participants may have muddied the findings. Specifically, research indicates that prominent sex differences exist in physiological measures of arousal (Gard \& Kring, 2007; Kring \& Gordon, 1998). Thus, combining results from males and females may have exaggerated and/or minimized aspects of the phenomena under investigation. Furthermore, the small sample size did not allow for analysis of the effect, if any, of sex on physiological indices.

Second, and most significantly, the vast majority of participants with BPD were taking psychoactive medications at the time of the laboratory task. The use of psychoactive medication may have masked differences between the two diagnostic groups. For example, SSRI administration has been shown to render differences in emotional reactivity between HCs and individuals with depression undetectable (Sheline, et al., 2001). Likewise, benzodiazepines are often prescribed for their sedating and muscle relaxing properties (Shorter, 2005). These same properties may have impeded participants' ability to attend to stimuli, and implement emotion regulation strategies. More important, however, the use of psychoactive medication may have dampened emotional responding across physiological measures. Indeed, this study hypothesized that individuals with BPD would show deficits in skill strengthening because of heightening emotional intensity. If, however, due to psychoactive medication, emotional intensity was dampened, the differences between groups may have been diminished, and thus making the effect of diagnostic status on skill strengthening more difficult to detect. It is important to note, however, that psychoactive medication use is typical in individuals with BPD in clinical samples. Thus, findings of skill strengthening from this study may more accurately generalize to treatment settings than had psychoactive medication use been an exclusion criterion. Finally, the present 
study used a single session design, which may not have allowed sufficient time for participants to acquire, consolidate, and strengthen emotion regulation strategies.

\section{Future Directions and Conclusion}

Future studies should build on this work in a number of ways. First, studies should examine if these findings are consistent across stimuli types (e.g., aural, visual, etc.). For example, previous studies suggest that idiographic stimuli may be more emotionally evocative than static images (Kuo, Neacsiu, Fitzpatrick \& MacDonald, 2014). It is possible that more emotionally evocative stimuli could impede skill strengthening as it may be more difficult to regulate higher intensity emotions.

Second, future studies should examine skill strengthening in the context of stimuli that evoke both high and low intensity emotional responses in both individuals with BPD and HCs. This manipulation would allow for further examination of the importance of arousal level in skill strengthening and provide support for the process model of emotion regulation in individuals with BPD (Scheppes, Scheibe, Suri \& Gross, 2011). Additionally, this manipulation would help determine the optimal conditions for skill strengthening both in individuals with BPD and HCs.

Third, subsequent investigations of emotion regulation skill strengthening should examine participants across multiple sessions. It is possible, for example, that the lack of findings in support of the hypotheses may be a result of the single session design used in the present study. Research from other therapeutic treatments (e.g. exposure therapy) has shown that change across sessions, rather than within session, is a better predictor of outcome (Jaycox, Foa $\&$ Morral, 1998). Furthermore, this research indicates that the absence of within-session change does not necessarily mean that the treatment has had no impact. Thus, it is possible that if tested 
in a subsequent session, HCs would show an improvement in mindful awareness, and individuals with BPD would show an improvement in distraction.

Fourth, given the high comorbidity present in individuals with BPD (Grant et al., 2008; Zanarini et al., 1998), moderators of skill strengthening should be examined. Due to their high occurrence in individuals with BPD, lifetime exposure to trauma, presence of childhood trauma, current or past PTSD diagnosis, current or past mood disorder, treatment history, and presence of another personality disorder are all potential moderators to be explored.

Fifth, future studies should consider using measures of central nervous system activation, such as fMRI and electroencephalography (EEG) to measure emotion regulation strategy implementation and strengthening. These techniques allow for a higher resolution examination of emotional responding, and the effects of specific strategies can be identified in a short period of time (e.g., within 5 seconds; Thiruchselvam, Blechert, Sheppes, Rydstrom \& Gross, 2011).

Finally, although the present study investigated the two most used emotion regulation strategies in DBT (i.e., distraction and mindful awareness) future studies should include multiple engagement and disengagement strategies to assess whether our findings generalize to other strategies (e.g., reappraisal).

In sum, the present study begins to illuminate the process of emotion regulation skill strengthening among individuals with BPD as compared to HCs. Contrary to hypotheses, individuals with BPD do not display deficits in emotion regulation skill strengthening. This finding, in addition to the finding that individuals with BPD are able to improve mindful awareness skills in a short period of time has several promising treatment applications. However, more research is needed to delineate fully the nature of emotion regulation skill strengthening in BPD. 
Table 1

Past and Current DSM-IV Axis I Diagnoses in the Borderline Personality Disorder Group

\begin{tabular}{lll}
\hline & Past & Current \\
\hline Other Bipolar Disorder & $4 \%$ & $4 \%$ \\
Major Depressive Disorder & $64 \%$ & $64 \%$ \\
Dysthymic Disorder & -- & $12 \%$ \\
Alcohol Abuse Disorder & $12 \%$ & $12 \%$ \\
Alcohol Dependence Disorder & $24 \%$ & $16 \%$ \\
Substance Abuse Disorder & $16 \%$ & $0 \%$ \\
Substance Dependence Disorder & $28 \%$ & $4 \%$ \\
Panic Disorder & See note & See note \\
Agoraphobia without a history of Panic Disorder & $16 \%$ & $16 \%$ \\
Social Anxiety Disorder & $4 \%$ & $24 \%$ \\
Specific Phobia & $8 \%$ & $0 \%$ \\
Obsessive Compulsive Disorder & $8 \%$ & $8 \%$ \\
Posttraumatic Stress Disorder & $12 \%$ & $12 \%$ \\
Anxiety Disorder Not Otherwise Specified & $24 \%$ & $24 \%$ \\
Generalized Anxiety Disorder & -- & $40 \%$ \\
Body Dysmorphic Disorder & $4 \%$ & $4 \%$ \\
Anorexia Nervosa & $12 \%$ & $0 \%$ \\
Bulimia Nervosa & $16 \%$ & $4 \%$ \\
\hline
\end{tabular}

Note. Due to a data entry error, data on the prevalence of panic disorder is missing. It is known

that $28 \%$ of participants had a history of panic disorder, but it is unclear how many of them currently met criteria for panic disorder at the time of the experiment. 
Table 2

Participant Demographics by Diagnostic Status

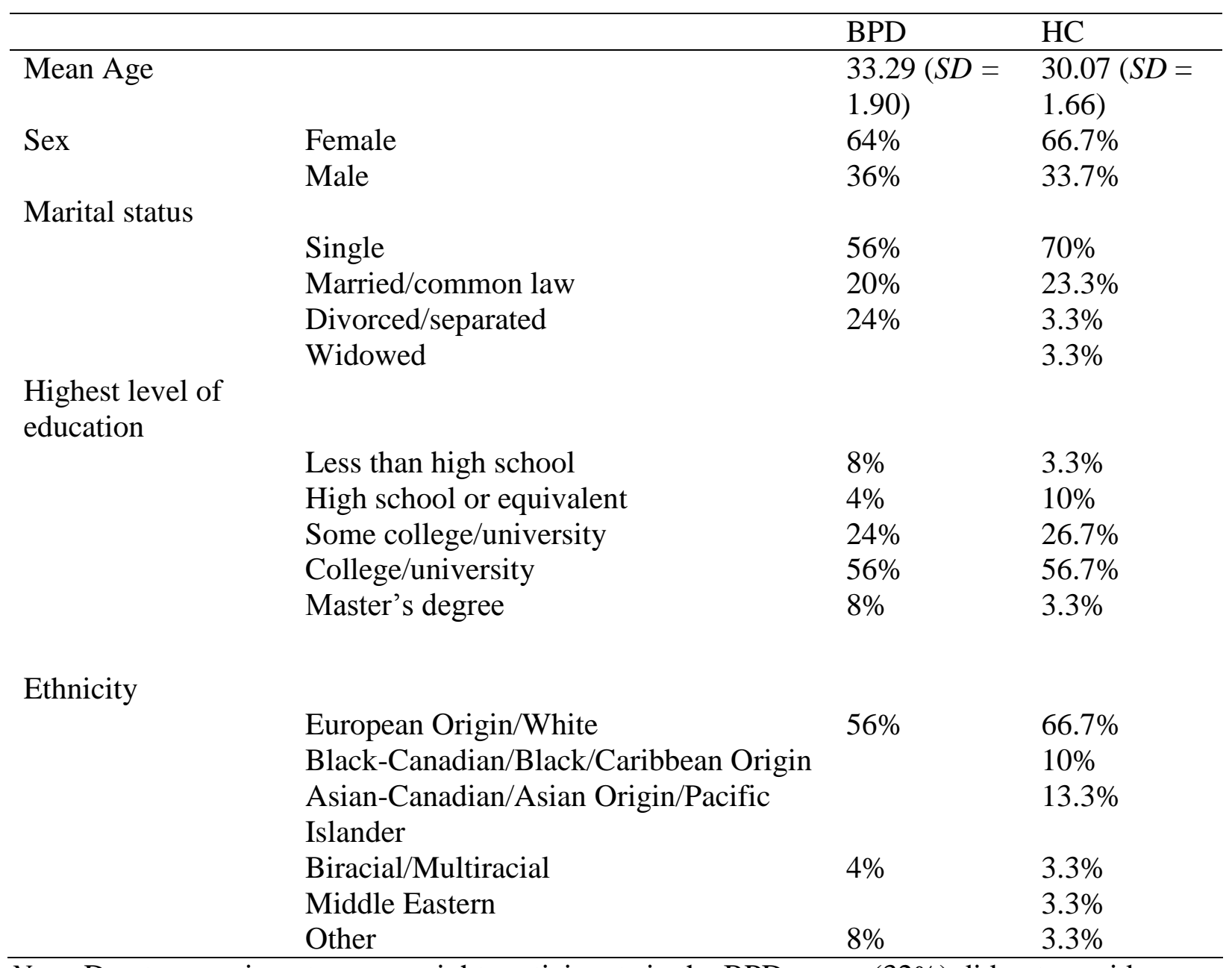

Note. Due to experimenter error, eight participants in the BPD group (32\%) did not provide ethnicity data and these data are thus missing. $\mathrm{BPD}=$ borderline personality disorder; $\mathrm{HC}=$ healthy control; $\mathrm{SD}=$ standard deviation. 
Table 3

Hierarchical Linear Modeling Fixed Effects for the Pairwise Comparison of Distraction and Reaction

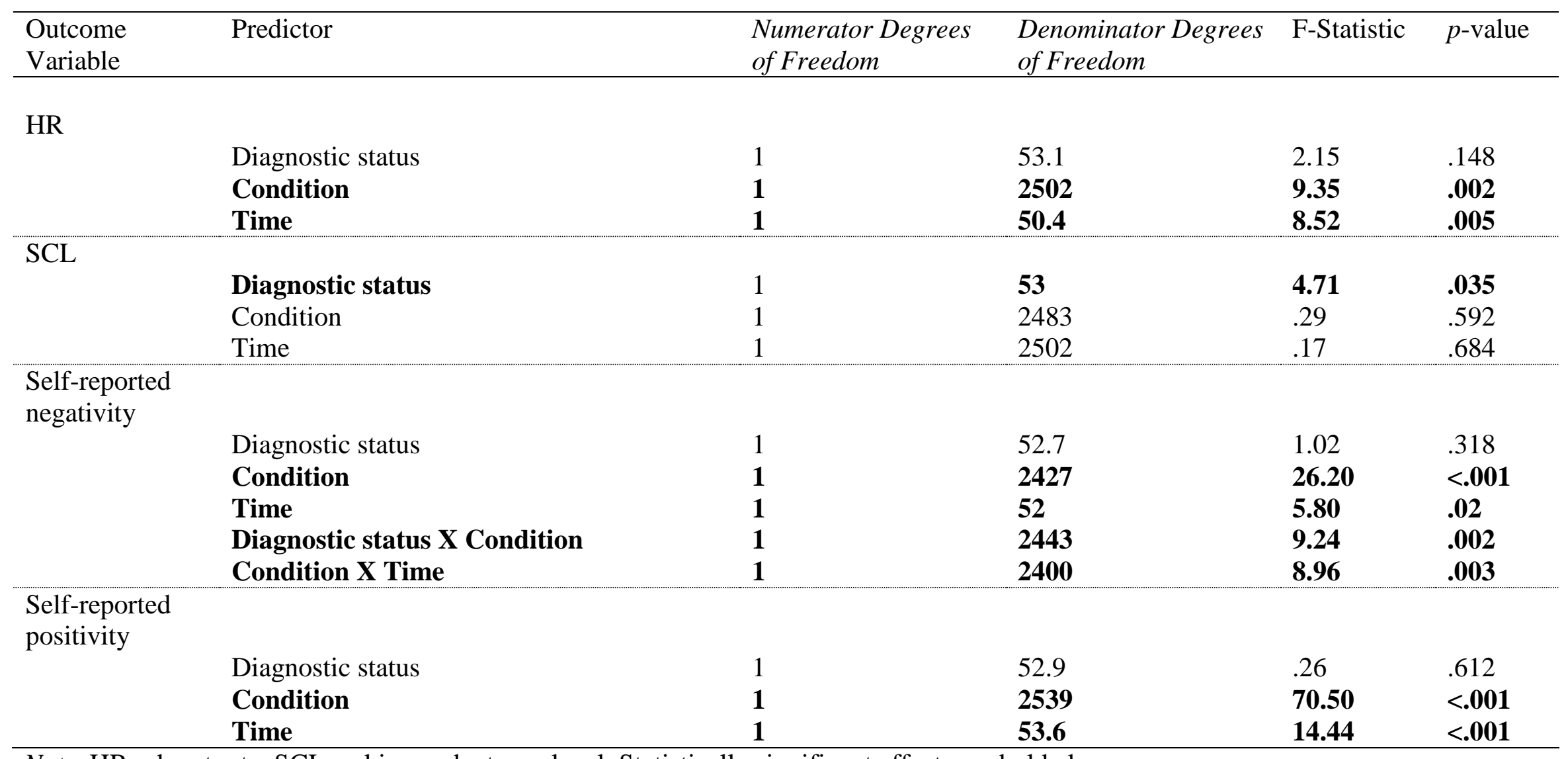

Note. $\mathrm{HR}=$ heart rate, $\mathrm{SCL}=$ skin conductance level. Statistically significant effects are bolded. 
Table 4

Hierarchical Linear Modeling Fixed Effects for the Pairwise Comparison of Mindful Awareness and Reaction

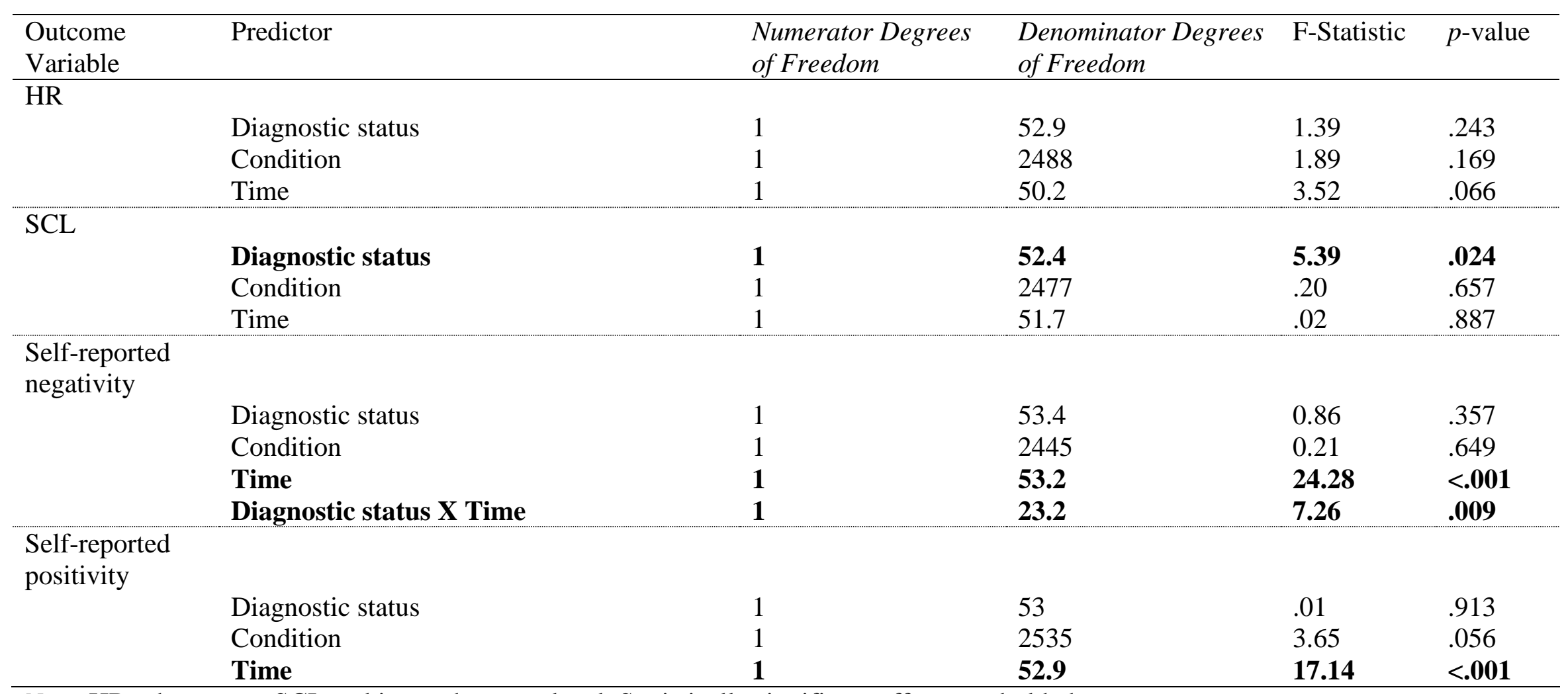

Note. $\mathrm{HR}=$ heart rate, $\mathrm{SCL}=$ skin conductance level. Statistically significant effects are bolded. 
Table 5

Hierarchical Linear Modeling Fixed Effects for the Pairwise Comparison of Distraction and Mindful Awareness

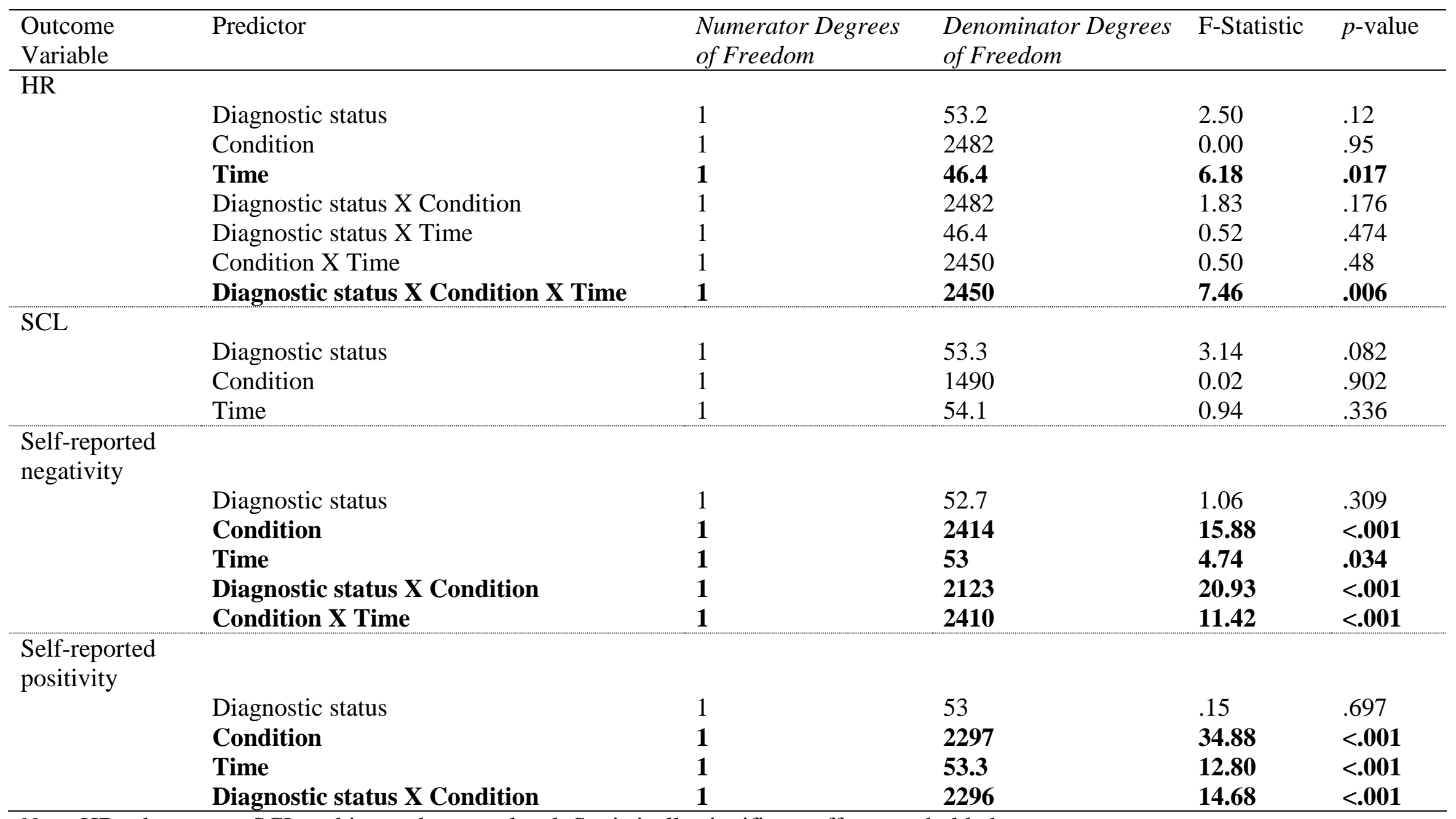

Note. $\mathrm{HR}=$ heart rate, $\mathrm{SCL}=$ skin conductance level. Statistically significant effects are bolded. 
Table 6

Means and Standard Deviations for the First and Last Segments of Each Condition for Each Outcome Variable, by Diagnostic Status

\begin{tabular}{|c|c|c|c|c|c|c|c|c|c|}
\hline \multirow[t]{2}{*}{ Condition } & \multirow[t]{2}{*}{ Outcome Variable } & \multicolumn{2}{|c|}{$\begin{array}{l}\text { BPD } \\
\text { First Trial }\end{array}$} & \multicolumn{2}{|c|}{$\begin{array}{l}\text { BPD } \\
\text { Last Trial }\end{array}$} & \multicolumn{2}{|c|}{$\begin{array}{l}\text { HC } \\
\text { First Trial }\end{array}$} & \multicolumn{2}{|c|}{$\begin{array}{l}\mathrm{HC} \\
\text { Last Trial }\end{array}$} \\
\hline & & Mean & $S D$ & Mean & $S D$ & Mean & $S D$ & Mean & $S D$ \\
\hline \multicolumn{10}{|l|}{ Reaction } \\
\hline & HR & 76.83 & 14.62 & 71.31 & 11.44 & 69.23 & 11.37 & 69.11 & 9.9 \\
\hline & SCL & -.12 & .19 & -.46 & .2 & -.23 & .57 & -.15 & .37 \\
\hline & $\begin{array}{l}\text { Self-reported } \\
\text { negativity }^{\mathrm{a}}\end{array}$ & 5.35 & 2.83 & 4.45 & 3.07 & 4.6 & 2.44 & 3.05 & 1.96 \\
\hline & $\begin{array}{l}\text { Self-reported } \\
\text { positivity }^{\mathrm{a}}\end{array}$ & 1.78 & 1.2 & 2.68 & 2.17 & 2.83 & 1.78 & 3.86 & 2.18 \\
\hline \multicolumn{10}{|l|}{ Distraction } \\
\hline & HR & 73.61 & 11.03 & 73.3 & 13.21 & 69.12 & 10.04 & 68.76 & 11.67 \\
\hline & SCL & -.01 & .33 & -.14 & .3 & .18 & .64 & .02 & .59 \\
\hline & $\begin{array}{l}\text { Self-reported } \\
\text { negativity }\end{array}$ & 3.52 & 2.79 & 4.11 & 2.11 & 3.53 & 2.37 & 5.33 & 1.93 \\
\hline & $\begin{array}{l}\text { Self-reported } \\
\text { positivity }\end{array}$ & 3.7 & 2.74 & 2.61 & 1.91 & 3.17 & 2.22 & 1.96 & 1.3 \\
\hline \multicolumn{10}{|l|}{$\begin{array}{l}\text { Mindful } \\
\text { Awareness }\end{array}$} \\
\hline & HR & 74.17 & 11.83 & 75.11 & 11.52 & 68.24 & 10.13 & 67.49 & 10.23 \\
\hline & SCL & -.06 & .17 & -.12 & .09 & -.07 & .65 & -.19 & .24 \\
\hline & $\begin{array}{l}\text { Self-reported } \\
\text { negativity }\end{array}$ & 3.96 & 2.9 & 4.12 & 2.8 & 4.6 & 2.24 & 4.94 & 2.54 \\
\hline & $\begin{array}{l}\text { Self-reported } \\
\text { positivity }\end{array}$ & 3.04 & 2.37 & 2.75 & 1.92 & 2.79 & 1.88 & 2.63 & 1.71 \\
\hline
\end{tabular}

Note $\mathrm{BPD}=$ borderline personality disorder, $\mathrm{HC}=$ healthy control, $\mathrm{HR}=$ heart rate, $\mathrm{SCL}=$ skin conductance level, $S D=$ standard

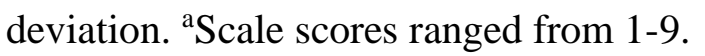



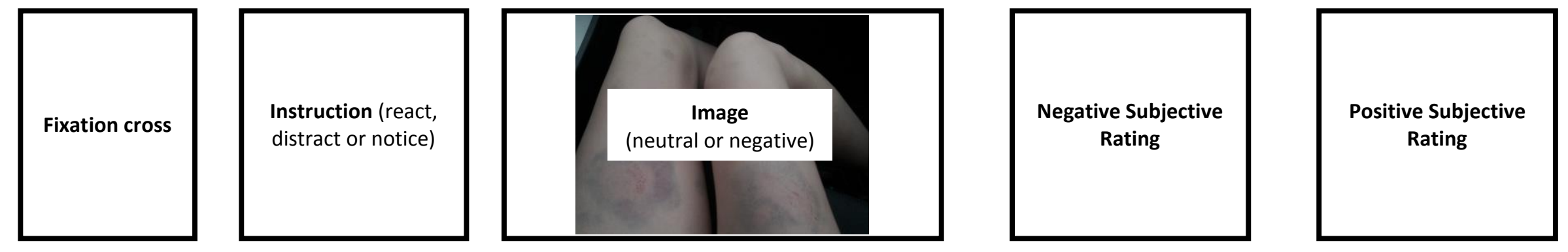

$2 s$

$2 s$

$10 \mathrm{~s}$

$4 \mathrm{~s}$

4s

Figure 1. Schematic illustration of a participant's experimental trial. 


\section{References}

American Psychiatric Association. (2013). Diagnostic and statistical manual of mental disorders (5th ed.). Washington, DC: American Psychiatric Association.

Appelhans, B. M., \& Luecken, L. J. (2006). Heart rate variability as an index of regulated emotional responding. Review of General Psychology, 10(3), 229-240. doi:http://dx.doi.org/10.1037/1089-2680.10.3.229

Arch, J. J., \& Craske, M. G. (2006). Mechanisms of mindfulness: Emotion regulation following a focused breathing induction. Behaviour Research and Therapy, 44(12), 1849-1858. doi:http://dx.doi.org/10.1016/j.brat.2005.12.007

Ballinger, G. A. (2004). Using generalized estimating equations for longitudinal data analysis. Organizational Research Methods, 7(2), 127-150. doi:http://dx.doi.org/10.1177/1094428104263672

Bijttebier, P., \& Vertommen, H. (1999). Coping strategies in relation to personality disorders. Personality and Individual Differences, 26(5), 847-856. Retrieved from http://ezproxy.lib.ryerson.ca/login?url=http://search.proquest.com/docview/619418363?acc ountid=13631

Bishop, S. R., Lau, M., Shapiro, S., Carlson, L., Anderson, N. D., Carmody, J., . . Devins, G. (2004). Mindfulness: A proposed operational definition. Clinical Psychology: Science and Practice, 11(3), 230-241. doi:http://dx.doi.org/10.1093/clipsy.bph077 Boucsein, W. (1992). Electrodermal Activity. New York: Plenum Press.

Braams, B. R., Blechert, J., Boden, M. T., \& Gross, J. J. (2012). The effects of acceptance and suppression on anticipation and receipt of painful stimulation. Journal of Behavior 
Therapy and Experimental Psychiatry, 43, 1014-1018. doi:

http://dx.doi.org/10.1016/j.jbtep.2012.04.001

Broderick, P. C. (2005). Mindfulness and coping with dysphoric mood: Contrasts with rumination and distraction. Cognitive Therapy and Research, 29(5), 501-510. doi:http://dx.doi.org/10.1007/s10608-005-3888-0

Campbell-Sills, L., Barlow, D. H., Brown, T. A., \& Hofmann, S. G. (2006). Effects of suppression and acceptance on emotional responses of individuals with anxiety and mood disorders. Behaviour Research and Therapy, 44(9), 1251-1263. doi:http://dx.doi.org/10.1016/j.brat.2005.10.001

Carter, G. L., Willcox, C. H., Lewin, T. J., Conrad, A. M., \& Bendit, N. (2010). Hunter DBT project: Randomized controlled trial of dialectical behaviour therapy in women with borderline personality disorder. Australian and New Zealand Journal of Psychiatry, 44(2), 162-173. doi:http://dx.doi.org/10.3109/00048670903393621

Chapman, A. L., Gratz, K. L., \& Brown, M. Z. (2006). Solving the puzzle of deliberate selfharm: The experiential avoidance model. Behaviour Research and Therapy, 44(3), 371394. doi:http://dx.doi.org/10.1016/j.brat.2005.03.005

Chapman, A. L., Specht, M. W., \& Cellucci, T. (2005). Borderline personality disorder and deliberate self-harm: Does experiential avoidance play a role? Suicide and LifeThreatening Behavior, 35(4), 388-399. doi:http://dx.doi.org/10.1521/suli.2005.35.4.388

Clarkin, J. F., Levy, K. N., Lenzenweger, M. F., \& Kernberg, O. F. (2007). Evaluating three treatments for borderline personality disorder: A multiwave study. The American Journal of Psychiatry, 164(6), 922-928. doi:http://dx.doi.org/10.1176/appi.ajp.164.6.922 
Coid, J., Yang, M., Tyrer, P., Roberts, A., \& Ullrich, S. (2006). Prevalence and correlates of personality disorder in great britain. The British Journal of Psychiatry, 188(5), 423-431. doi:http://dx.doi.org/10.1192/bjp.188.5.423

Coles, M. E., \& Heimberg, R. G. (2000). Patterns of anxious arousal during exposure to feared situations in individuals with social phobia. Behaviour research and therapy, 38(4), 40524. Retrieved from http://www.ncbi.nlm.nih.gov/pubmed/10761283

Conklin, C. Z., Bradley, R., \& Westen, D. (2006). Affect regulation in borderline personality disorder. Journal of Nervous and Mental Disease, 194, 69-77. doi: http://dx.doi.org/10.1097/01.nmd.0000198138.41709.4f

Conklin, C. Z., \& Westen, D. (2005). Borderline personality disorder in clinical practice. The American Journal of Psychiatry, 162(5), 867-875. doi:http://dx.doi.org/10.1176/appi.ajp.162.5.867

Davidson, R. J. (2002). Anxiety and affective style: role of prefrontal cortex and amygdala. Biological psychiatry, 51(1), 68-80. Retrieved from http://www.ncbi.nlm.nih.gov/pubmed/11801232

Davis, M., \& Whalen, P. J. (2001). The amygdala: vigilance and emotion. Molecular psychiatry, 6(1), 13-34. Retrieved from http://www.ncbi.nlm.nih.gov/pubmed/11244481

De Jong, M. C., \& Boersma, C. H. (2010). Device-guided breathing as a possible tool to improve the outcome of exposure therapy. Mental Illness, 2(1), 9-11. doi:10.4081/mi.2010.e6

Donegan, N. H., Sanislow, C. a, Blumberg, H. P., Fulbright, R. K., Lacadie, C., Skudlarski, P., Gore, J. C., et al. (2003). Amygdala hyperreactivity in borderline personality disorder: implications for emotional dysregulation. Biological Psychiatry, 54(11), 1284-1293. doi:10.1016/S0006-3223(03)00636-X 
Ebner-Priemer, Ulrich W., Kuo, J., Kleindienst, N., Welch, S. S., Reisch, T., ... Bohus, M. (2007). State affective instability in borderline personality disorder assessed by ambulatory monitoring. Psychological Medicine: A Journal of Research in Psychiatry and the Allied Sciences, 37, 961-970. doi:10.1017/S0033291706009706

Eckman, P. S., \& Shean, G. D. (1997). Habituation of cognitive and physiological arousal and social anxiety. Behaviour research and therapy, 35(12), 1113-21. Retrieved from http://www.ncbi.nlm.nih.gov/pubmed/946544

Elices, M., Soler, J., Fernández, C., Martín-Blanco, A., Jesús Portella, M., Pérez, V., . . Carlos Pascual, J. (2012). Physiological and self-assessed emotional responses to emotioneliciting films in borderline personality disorder. Psychiatry Research, 200, 437-443. doi:http://dx.doi.org.ezproxy.lib.ryerson.ca/10.1016/j.psychres.2012.07.020

Feingold, A. (2009). Effect sizes for growth-modeling analysis for controlled clinical trials in the same metric as for classical analysis. Psychological Methods, 14(1), 43-53. doi:http://dx.doi.org/10.1037/a0014699

Foa, Edna B. (2011). Prolonged exposure therapy: past, present, and future. Depression and anxiety, 28(12), 1043-7. doi:10.1002/da.20907

Fonagy, P., Target, M., \& Gergely, G. (2000). Attachment and borderline personality disorder: A theory and some evidence.Psychiatric Clinics of North America, 23(1), 103-122. Retrieved from http://ezproxy.lib.ryerson.ca/login?url=http://search.proquest.com/docview/ 619454677? accountid=13631

Fowles, D. C., Christie, M. J., Edelberg, R., Grings, W. W., Lykken, D. T., \& Venables, P. H. (1981). Publication recommendations for electrodermal measurements. Psychophysiology, 
18, 232-239. doi:http://dx.doi.org.ezproxy.lib.ryerson.ca/10.1111/j.1469-

8986.1981.tb03024.x

Gallagher, M., \& Chiba, A. A. (1996). The amygdala and emotion. Current opinion in neurobiology, 6(2), 221-7. Retrieved from http://www.ncbi.nlm.nih.gov/pubmed/8725964

Gard, M. G., \& Kring, A. M. (2007). Sex differences in the time course of emotion. Emotion, 7(2), 429-437. doi:http://dx.doi.org/10.1037/1528-3542.7.2.429

Geller, J. L. (1986). In again, out again: Preliminary evaluation of a state hospital's worst recidivists. Hospital \& Community Psychiatry, 37(4), 386-390. Retrieved from http://ezproxy.lib.ryerson.ca/login?url=http://search.proquest.com/docview/617217744?acc ountid=13631

Ghisletta, P., \& Spini, D. (2004). An introduction to generalized estimating equations and an application to assess selectivity effects in a longitudinal study on very old individuals. Journal of Educational and Behavioral Statistics, 29(4), 421-437. doi:http://dx.doi.org/10.3102/10769986029004421

Glenn, C. R., \& Klonsky, E. D. (2009). Emotion dysregulation as a core feature of borderline personality disorder. Journal of Personality Disorders, 23, 20-28. doi:http://dx.doi.org/10.1521/pedi.2009.23.1.20

Goodman, M., Carpenter, D., Tang, C. Y., Goldstein, K. E., Avedon, J., Fernandez, N., ... Hazlett, E. A. (2014). Dialectical behavior therapy alters emotion regulation and amygdala activity in patients with borderline personality disorder. Journal of Psychiatric Research, doi:http://dx.doi.org/10.1016/j.jpsychires.2014.06.020 
Goldin, P. R., McRae, K., Ramel, W., \& Gross, J. J. (2008). The neural bases of emotion regulation: Reappraisal and suppression of negative emotion. Biological Psychiatry, 63(6), 577-586. doi:http://dx.doi.org/10.1016/j.biopsych.2007.05.031

Grant, B. F., Chou, S. P., Goldstein, R. B., Huang, B., Stinson, F. S., Saha, T. D., . . Ruan, W. J. (2008). Prevalence, correlates, disability, and comorbidity of DSM-IV borderline personality disorder: Results from the wave 2 national epidemiologic survey on alcohol and related conditions. Journal of Clinical Psychiatry, 69, 533-545. doi: http://dx.doi.org/10.4088/JCP.v69n0404

Gratz, K. L., Rosenthal, M. Z., Tull, M. T., Lejuez, C. W., \& Gunderson, J. G. (2010). An experimental investigation of emotional reactivity and delayed emotional recovery in borderline personality disorder: The role of shame. Comprehensive Psychiatry, 51, 275285. doi: http://dx.doi.org/10.1016/j.comppsych.2009.08.005

Gross, J. J. (1998). The emerging field of emotion regulation: An integrative review. Review of General Psychology, 2, 271-299.

Gross, J. J. (2002). Emotion regulation: Affective, cognitive, and social consequences. Psychophysiology, 39, 281-291. doi: http://dx.doi.org/10.1017/S0048577201393198

Gross, J. J., \& John, O. P. (2003). Individual differences in two emotion regulation processes: Implications for affect, relationships, and well-being. Journal of Personality and Social Psychology, 85(2), 348-362. doi:http://dx.doi.org/10.1037/0022-3514.85.2.348

Gross, J. J., \& Levenson, R. W. (1993). Emotional suppression: Physiology, self-report, and expressive behavior. Journal of Personality and Social Psychology, 64(6), 970-986. doi:http://dx.doi.org/10.1037/0022-3514.64.6.970 
Gunderson, J. G. (2011). Borderline personality disorder. The New England Journal of Medicine, 364(21), 2037-2042.

Hardin, J. W., \& Hilbe, J. M. (2002). Generalized Estimating Equations. Boca Roton, Florida: CRC Press.

Hayes, A, M.., \& Feldman, G. (2004). Clarifying the construct of mindfulness in the context of emotion regulation and the process of change in therapy. Clinical Psychology: Science and Practice, 11(3), 255-262. doi:http://dx.doi.org/10.1093/clipsy.bph080

Hayes, S. C., Wilson, K. G., Gifford, E. V., Follette, V. M., \& Strosahl, K. (1996). Experiential avoidance and behavioral disorders: A functional dimensional approach to diagnosis and treatment. Journal of Consulting and Clinical Psychology, 64(6), 1152-1168.

doi:http://dx.doi.org/10.1037/0022-006X.64.6.1152

Herpertz, S. C., Dietrich, T. M., Wenning, B., Krings, T., Erberich, S. G., Willmes, K., ... Sass, H. (2001). Evidence of abnormal amygdala functioning in borderline personality disorder: A functional MRI study. Biological Psychiatry, 50(4), 292-298. doi:http://dx.doi.org/10.1016/S0006-3223(01)01075-7

Herpertz, S. C., Kunert, H. J., Schwenger, U. B., \& Sass, H. (1999). Affective responsiveness in borderline personality disorder: A psychophysiological approach. The American Journal of Psychiatry, 156, 1550-1556.

Hodgson, R., \& Rachman, S. (1974). II. desynchrony in measures of fear. Behaviour Research and Therapy, 12(4), 319-326. Retrieved from http://ezproxy.lib.ryerson.ca/login?url=http:// search.proquest.com/docview/1285630316?accountid=13631 
Hofmann, S. G., Heering, S., Sawyer, A. T., \& Asnaani, A. (2009). How to handle anxiety: The effects of reappraisal, acceptance, and suppression strategies on anxious arousal. Behaviour Research and Therapy, 47, 389-394. doi: http://dx.doi.org/10.1016/j.brat.2009.02.010

Huffziger, S., Reinhard, I., \& Kuehner, C. (2009). A longitudinal study of rumination and distraction in formerly depressed inpatients and community controls. Journal of Abnormal Psychology, 118(4), 746-756. doi:http://dx.doi.org/10.1037/a0016946

Ingjaldsson, J. T., Laberg, J. C., \& Thayer, J. F. (2003). Reduced heart rate variability in chronic alcohol abuse: Relationship with negative mood, chronic thought suppression, and compulsive drinking. Biological Psychiatry, 54(12), 1427-1436. doi:http://dx.doi.org/10.1016/S0006-3223(02)01926-1

Jackson, J. C. (1974). Amplitude and habituation of the orienting reflex as a function of stimulus intensity. Psychophysiology, 11(6), 647-659. Retrieved from http://ezproxy.lib.ryerson.ca/ login?url=http://search.proquest.com/docview/615986162?accountid=13631

Jacob, G. A., Arendt, J., Kolley, L., Scheel, C. N., Bader, K., Lieb, K., . . Tüscher, O. (2011). Comparison of different strategies to decrease negative affect and increase positive affect in women with borderline personality disorder. Behaviour Research and Therapy, 49, 6873. doi: http://dx.doi.org/10.1016/j.brat.2010.10.005

Jaycox, L. H., Foa, E. B., \& Morral, A. R. (1998). Influence of emotional engagement and habituation on exposure therapy for PTSD. Journal of Consulting and Clinical Psychology, 66(1), 185-192. doi:http://dx.doi.org/10.1037/0022-006X.66.1.185

Judd, P. H., \& McGlashan, T. H. (2003). A developmental model of borderline personality disorder: Understanding variations in course and outcome American Psychiatric 
Publishing, Inc., Arlington, VA. Retrieved from http://ezproxy.lib.ryerson.ca/ login?url=http://search.proquest.com/docview/620128891?accountid=13631

Kabat-Zinn, J. (1990). Full catastrophe living: Using the wisdom of your body and mind to face stress, pain, and illness. New York, N.Y.: Dell Publishing.

Kaplan, J. S., \& Tolin, D. F. (2011). Theoretical Mechanisms of Exposure and Treatment Strategies. Psychiatric Times, 28(9), 33-37.

Koenigsberg, H. W., Fan, J., Ochsner, K. N., Liu, X., Guise, K. G., Pizzarello, S., . . Siever, L. J. (2009). Neural correlates of the use of psychological distancing to regulate responses to negative social cues: A study of patients with borderline personality disorder. Biological Psychiatry, 66, 854-863. doi:http://dx.doi.org/10.1016/j.biopsych.2009.06.010

Kring, A. M., \& Gordon, A. H. (1998). Sex differences in emotion: Expression, experience, and physiology. Journal of Personality and Social Psychology, 74(3), 686-703. doi:http://dx.doi.org/10.1037/0022-3514.74.3.686

Kruedelbach, N., McCormick, R. A., Schulz, S. C., \& Grueneich, R. (1993). Impulsivity, coping styles, and triggers for craving in substance abusers with borderline personality disorder. Journal of Personality Disorders, 7(3), 214-222. Retrieved from http://ezproxy.lib.ryerson.ca/login?url=http://search.proquest.com/docview/618439482?acc ountid=13631

Kuehner, C., Huffziger, S., \& Liebsch, K. (2009). Rumination, distraction and mindful selffocus: Effects on mood, dysfunctional attitudes and cortisol stress response. Psychological Medicine, 39(2), 219-228. doi:http://dx.doi.org/10.1017/S0033291708003553

Kuo, J. R., Fitzpatrick, S., Metcalfe, R. K., \& McMain, S. (2013, November). A Multi-Method Investigation of Emotion Regulation Capabilities in Borderline Personality Disorder: 
Comparison of Distraction and Acceptance. Paper presented at the annual convention of the Association for Behavioral and Cognitive Therapies. Nashville, United States of America.

Kuo, J. R., \& Linehan, M. M. (2009). Disentangling emotion processes in borderline personality disorder: Physiological and self-reported assessment of biological vulnerability, baseline intensity, and reactivity to emotionally evocative stimuli. Journal of Abnormal Psychology, 118, 531-544. doi: http://dx.doi.org/10.1037/a0016392

Kuo, J. R., Neacsiu, A. D., Fitzpatrick, S., \& MacDonald, D. E. (2013). A methodological examination of emotion inductions in borderline personality disorder: A comparison of standardized versus idiographic stimuli. Journal of Psychopathology and Behavioral Assessment, doi: http://dx.doi.org/10.1007/s10862-013-9378-x

Kusumoto, F. (2009). ECG interpretation: from pathophysiology to clinical application. New York: Springer.

Lader, M. H., \& Wing, L. (1966). Physiological Measures, Sedative Drugs, and Morbid Anxiety. London: Oxford University Press.

Lang, P. J., Bradley, M. M., \& Cuthbert, B. N. (2008). International affective picture system (IAPS): Affective ratings of pictures and instruction manual. Technical Report A-8.

Lang, S., Kotchoubey, B., Frick, C., Spitzer, C., Grabe, H. J., \& Barnow, S. (2012). Cognitive reappraisal in trauma-exposed women with borderline personality disorder. Neuroimage, 59, 1727-1734. doi: http://dx.doi.org/10.1016/j.neuroimage.2011.08.061

Levine, D., Marziali, E., \& Hood, J. (1997). Emotion processing in borderline personality disorders. Journal of Nervous and Mental Disease, 185(4), 240-246. Retrieved from 
http://ezproxy.lib.ryerson.ca/login?url=http://search.proquest.com/docview/619068297?acc ountid=13631

Lieb, K., Zanarini, M. C., Schmahl, C., Linehan, M. M., \& Bohus, M. (2004). Borderline personality disorder. The Lancet, 364(9432) doi:http://dx.doi.org/10.1016/S01406736(04)16770-6

Limberg, A., Barnow, S., Freyberger, H. J., \& Hamm, A. O. (2011). Emotional vulnerability in borderline personality disorder is cue specific and modulated by traumatization. Biological Psychiatry, 69(6), 574-582. doi:http://dx.doi.org/10.1016/j.biopsych.2010.10.024

Lindenboim, N., Comtois, K. A., \& Linehan, M. M. (2007). Skills practice in dialectical behavior therapy for suicidal women meeting criteria for borderline personality disorder. Cognitive and Behavioral Practice, 14, 147-156. doi:http://dx.doi.org.ezproxy.lib.ryerson.ca/10.1016/j.cbpra.2006.10.004

Linehan, M. M. (1993). Cognitive-behavioral treatment of borderline personality disorder. New York, NY, US: Guilford Press, New York, NY.

Linehan, M. M., Armstrong, H. E., Suarez, A., Allmon, D., \& Heard, H. L. (1991). Cognitivebehavioral treatment of chronically parasuicidal borderline patients. Archives of General Psychiatry, 48(12), 1060-1064. Retrieved from http://ezproxy.lib.ryerson.ca/ login?url=http://search.proquest.com/docview/618103986?accountid=13631

Linehan, M. M., Comtois, K. A., Murray, A. M., Brown, M. Z., Gallop, R. J., Heard, H. L., . . Lindenboim, N. (2006). Two-year randomized controlled trial and follow-up of dialectical behavior therapy vs therapy by experts for suicidal behaviors and borderline personality disorder. Archives of General Psychiatry, 63(7), 757-766. doi:http://dx.doi.org/10.1001/archpsyc.63.7.757 
Linehan, M. M., Dimeff, L. A., Reynolds, S. K., Comtois, K. A., Welch, S. S., Heagerty, P., \& Kivlahan, D. R. (2002). Dialectical behavior therapy versus comprehensive validation therapy plus 12-step for the treatment of opioid dependent women meeting criteria for borderline personality disorder. Drug and Alcohol Dependence, 67(1), 13-26. doi:http://dx.doi.org/10.1016/S0376-8716(02)00011-X

Linehan, M. M., Schmidt, H., Dimeff, L. A., Craft, J. C., Kanter, J., \& Comtois, K. A. (1999). Dialectical behavior therapy for patients with borderline personality disorder and drugdependence. The American Journal on Addictions, 8(4), 279-292. Retrieved from http://ezproxy.lib.ryerson.ca/login?url=http://search.proquest.com/docview/619490434?acc ountid=13631

Littell, R. C., Pendergast, J., \& Natarajan, R. (2000). Modelling covariance structure in analysis of repeated measures data. Statistics in Medicine, 19, 1793-1819.

Lobbestael, J., Leurgans, M., \& Arntz, A. (2011). Inter-rater reliability of the structured clinical interview for DSM-IV axis I disorders (SCID I) and axis II disorders (SCID II). Clinical Psychology \& Psychopathology, 18, 75-79. doi:http://dx.doi.org.ezproxy.lib.ryerson.ca/10.1002/cpp.693

Loranger, A. W., Sartorius, N., Andreoli, A., Berger, P., Buchheim, P., Channabasavanna, S. M., ... Regier, D. A. (1994). The international personality disorder examination: The world health Organization/Alcohol, drug abuse, and mental health administration international pilot study of personality disorders. Archives of General Psychiatry, 51, 215-224. doi:http://dx.doi.org.ezproxy.lib.ryerson.ca/10.1001/archpsyc.1994.03950030051005 
Lynch, T. R., Rosenthal, M. Z., Kosson, D. S., Cheavens, J. S., Lejuez, C. W., \& Blair, R. J. R. (2006). Heightened sensitivity to facial expressions of emotion in borderline personality disorder. Emotion, 6(4), 647-655. doi:http://dx.doi.org/10.1037/1528-3542.6.4.647

Mann, A. H., Raven, P., Pilgrim, J., Khanna, S., Velayudham, A., Suresh, K. P., . . Sartorius, N. (1999). An assessment of the standardized assessment of personality as a screening instrument for the international personality disorder examination: A comparison of informant and patient assessment for personality disorder. Psychological Medicine, 29, 985-989. doi:http://dx.doi.org.ezproxy.lib.ryerson.ca/10.1017/S0033291798007545

Marissen, M. A. E., Meuleman, L., \& Franken, I. H. A. (2010). Altered emotional information processing in borderline personality disorder: An electrophysiological study. Psychiatry Research: Neuroimaging, 181, 226-232. doi: http://dx.doi.org/10.1016/j.pscychresns.2009.10.006

Mauss, I. B., Levenson, R. W., McCarter, L., Wilhelm, F. H., \& Gross, J. J. (2005). The tie that binds? coherence among emotion experience, behavior, and physiology. Emotion, 5(2), 175-190. doi:http://dx.doi.org/10.1037/1528-3542.5.2.175

Mauss, I. B., \& Robinson, M. D. (2009). Measures of emotion: A review. Cognition and Emotion, 23(2), 209-237. doi:http://dx.doi.org/10.1080/02699930802204677

McGlashan, T. H., Grilo, C. M., Skodol, A. E., Gunderson, J. G., Shea, M. T., Morey, L. C., . . . Stout, R. L. (2000). The collaborative longitudinal personality disorders study: Baseline axis I/II and II/II diagnostic co-occurrence. Acta Psychiatrica Scandinavica, 102(4), 256264. doi:http://dx.doi.org/10.1034/j.1600-0447.2000.102004256.x

McKay, D., Todaro, J., Neziroglu, F., Campisi, T., Moritz, E. K., \& Yaryura-Tobias, J. A. (1997). Body dysmorphic disorder: a preliminary evaluation of treatment and maintenance 
using exposure with response prevention. Behaviour Research and Therapy, 35(1), 67-70. doi:10.1016/S0005-7967(96)00082-4

McMain, S. F., Guimond, T., Streiner, D. L., Cardish, R. J., \& Links, P. S. (2012). Dialectical behavior therapy compared with general psychiatric management for borderline personality disorder: Clinical outcomes and functioning over a 2-year follow-up. The American Journal of Psychiatry, 169(6), 650-661. Retrieved from http://ezproxy.lib.ryerson.ca/ login?url=http://search.proquest.com/docview/1036889464?accountid=13631

McMain, S. F., Links, P. S., Gnam, W. H., Guimond, T., Cardish, R. J., Korman, L., \& Streiner, D. L. (2009). A randomized trial of dialectical behavior therapy versus general psychiatric management for borderline personality disorder. The American Journal of Psychiatry, 166(12), 1365-1374. doi:http://dx.doi.org/10.1176/appi.ajp.2009.09010039

Medhanie, A. G. (2014). The robustness of multilevel multiple imputation for handling missing data in hierarchical linear models. (Order No. AAI3589097, Dissertation Abstracts International: Section B: The Sciences and Engineering, Retrieved from http://ezproxy.lib.ryerson.ca/login?url=http://search.proquest.com/docview/1534280883?a ccountid=13631. $(1534280883 ; 2014-99100-510)$.

Perseius, K., Ekdahl, S., Åsberg, M., \& Samuelsson, M. (2005). To tame a volcano: Patients with borderline personality disorder and their perceptions of suffering. Archives of Psychiatric Nursing, 19(4), 160-168. doi:http://dx.doi.org/10.1016/j.apnu.2005.05.001

Pompili, M., Girardi, P., Ruberto, A., \& Tatarelli, R. (2005). Suicide in borderline personality disorder: A meta-analysis. Nordic Journal of Psychiatry, 59(5), 319-324. doi:http://dx.doi.org/10.1080/08039480500320025 
Rachman, S., \& Hodgson, R. (1974). I. synchrony and desynchrony in fear and avoidance. Behaviour Research and Therapy, 12(4), 311-318. Retrieved from http://ezproxy.lib.ryerson.ca/login?url=http://search.proquest.com/docview/1285630315?a ccountid=13631

Raudenbush, S. W. (1993). Hierarchical linear models and experimental design. Applied analysis of variance in behavioral science. (pp. 459-496) Marcel Dekker, New York, NY. Retrieved from http://ezproxy.lib.ryerson.ca/login?url=http://search.proquest.com/docview/ 618400306 ?accountid=13631

Raudenbush, S. W. (2004). What are value-added models estimating and what does this imply for statistical practice? Journal of Educational and Behavioral Statistics, 29(1), 121-129. doi:http://dx.doi.org/10.3102/10769986029001121

Raudenbush, S. W., \& Bryk, A. W. (2002). Hierarchical linear models: Applications and data analysis methods $2^{\text {nd }} E d$. Newbury Park, CA, US: Sage Publishing.

Robins, C. J., \& Chapman, A. L. (2004). Dialectical behavior therapy: current status, recent developments, and future directions. Journal of personality disorders, 18(1), 73-89. Retrieved from http://www.ncbi.nlm.nih.gov/pubmed/15061345

Rodriguez, B. I., \& Craske, M. G. (1993). The effects of distraction during exposure to phobic stimuli. Behaviour research and therapy, 31(6), 549-58.

Roozendaal, B., McEwen, B. S., \& Chattarji, S. (2009). Stress, memory and the amygdala. Nature reviews. Neuroscience, 10(6), 423-33. doi:10.1038/nrn2651

Rosenthal, M. Z., Ahn, R., \& Geiger, P. J. (2011). Reactivity to sensations in borderline personality disorder: A preliminary study. Journal of Personality Disorders, 25(5), 715721. doi:http://dx.doi.org/10.1521/pedi.2011.25.5.715 
Ruocco, A. C., Medaglia, J. D., Ayaz, H., \& Chute, D. L. (2010). Abnormal prefrontal cortical response during affective processing in borderline personality disorder. Psychiatry Research: Neuroimaging, 182, 117-122. doi:

http://dx.doi.org/10.1016/j.pscychresns.2010.01.011

Schmahl, C., Herpertz, S. C., Bertsch, K., Ende, G., Flor, H., Kirsch, P., . . . Bohus, M. (2014). Mechanisms of disturbed emotion processing and social interaction in borderline personality disorder: State of knowledge and research agenda of the German Clinical Research Unit. Borderline Personality Disorder and Emotion Dysregulation, 1, 1-17.

Scott, L. N., Levy, K. N., \& Granger, D. A. (2013). Biobehavioral reactivity to social evaluative stress in women with borderline personality disorder. Personality Disorders: Theory, Research, and Treatment, 4(2), 91-100. doi:http://dx.doi.org/10.1037/a0030117

Selby, E. A., \& Joiner, T. E., Jr. (2009). Cascades of emotion: The emergence of borderline personality disorder from emotional and behavioral dysregulation. Review of General Psychology, 13, 219-229. doi: http://dx.doi.org/10.1037/a0015687

Sheline, Y. I., Barch, D. M., Donnelly, J. M., Ollinger, J. M., Snyder, A. Z., \& Mintun, M. A. (2001). Increased amygdala response to masked emotional faces in depressed subjects resolves with antidepressant treatment: An fMRI study. Biological Psychiatry, 50(9), 651658. doi:http://dx.doi.org/10.1016/S0006-3223(01)01263-X

Sheppes, G., Scheibe, S., Suri, G., \& Gross, J. J. (2011). Emotion-regulation choice. Psychological Science, 22(11), 1391-1396. doi:http://dx.doi.org/10.1177/0956797611418350 
Shorter, E. (2005). A historical dictionary of psychiatry Oxford University Press, New York, NY. Retrieved from http://ezproxy.lib.ryerson.ca/login?url=http://search.proquest.com/ docview/620740604?accountid=13631

Singer, A. R., \& Dobson, K. S. (2007). An experimental investigation of the cognitive vulnerability to depression. Behaviour Research and Therapy, 45(3), 563-575. doi:http://dx.doi.org/10.1016/j.brat.2006.05.007

Sloan, D. M., Sege, C. T., McSweeney, L. B., Suvak, M. K., Shea, M. T., \& Litz, B. T. (2010). Development of a borderline personality disorder-relevant picture stimulus set. Journal of Personality Disorders, 24, 664-675. doi:http://dx.doi.org/10.1521/pedi.2010.24.5.664

Thiruchselvam, R., Blechert, J., Sheppes, G., Rydstrom, A., \& Gross, J. J. (2011). The temporal dynamics of emotion regulation: An EEG study of distraction and reappraisal. Biological Psychology, 87, 84-92. doi: http://dx.doi.org/10.1016/j.biopsycho.2011.02.009

Urry, H. L. (2010). Seeing, thinking, and feeling: Emotion-regulating effects of gaze-directed cognitive reappraisal. Emotion,10(1), 125-135. doi:http://dx.doi.org/10.1037/a0017434

Van Busschbach, J. (2012). Health Economics and borderline personality disorders: Methods, arguments and perspectives. Paper presented at The $2^{\text {nd }}$ International Congress on Borderline Personality Disorder and Allied Disorders. Amsterdam, Netherlands.

Van Minnen, A., \& Hagenaars, M. (2002). Fear activation and habituation patterns as early process predictors of response to prolonged exposure treatment in PTSD. Journal of traumatic stress, 15(5), 359-67. doi:10.1023/A:1020177023209

Ventura, J., Liberman, R. P., Green, M. F., Shaner, A., \& Mintz, J. (1998). Training and quality assurance with structured clinical interview for DSM-IV (SCID-I/P). Psychiatry Research, 79, 163-173. doi:http://dx.doi.org.ezproxy.lib.ryerson.ca/10.1016/S0165-1781(98)00038-9 
Verheul, R., van, d. B., Koeter, M. W. J., de Ridder, Maria A. J., Stijnen, T., \& van, d. B. (2003). Dialectical behaviour therapy for women with borderline personality disorder: 12-month, randomized clinical trial in the Netherlands. The British Journal of Psychiatry, 182(2), 135-140. doi:http://dx.doi.org/10.1192/bjp.182.2.135

Welch, S. S., Linehan, M. M., Sylvers, P., Chittams, J., \& Rizvi, S. L. (2008). Emotional responses to self-injury imagery among adults with borderline personality disorder. Journal of Consulting and Clinical Psychology, 76(1), 45-51. doi:http://dx.doi.org/10.1037/0022-006X.76.1.45

Westen, D., Muderrisoglu, S., Fowler, C., Shedler, J., \& Koren, D. (1997). Affect regulation and affective experience: Individual differences, group differences, and measurement using a Q-sort procedure. Journal of Consulting and Clinical Psychology, 65, 429-439. doi: http://dx.doi.org/10.1037/0022-006X.65.3.429

Willms, J. D. (1999). Basic concepts in hierarchical linear modeling with applications for policy analysis. In G. Cizek (Ed.),Handbook of Educational Policy (pp. 473-493). New York: Academic Press.

Wolgast, M., Lundh, L., \& Viborg, G. (2013). Experiential avoidance as an emotion regulatory function: An empirical analysis of experiential avoidance in relation to behavioral avoidance, cognitive reappraisal, and response suppression. Cognitive Behaviour Therapy, 42(3), 224-232. doi:http://dx.doi.org/10.1080/16506073.2013.773059

Woltman, H., Feldstain, A., MacKay, J. C., \& Rocchi, M. (2012). An introduction to hierarchical linear modeling. Tutorials in Quantitative Methods for Psychology, 8(1), 52-69. 
Woollaston, K., \& Hixenbaugh, P. (2008). 'Destructive whirlwind': Nurses' perceptions of patients diagnosed with borderline personality disorder. Journal of Psychiatric and Mental Health Nursing, 15(9), 703-709. doi:http://dx.doi.org/10.1111/j.1365-2850.2008.01275.x

Yen, S., Zlotnick, C., \& Costello, E. (2002). Affect regulation in women with borderline personality disorder traits. Journal of Nervous and Mental Disease, 190(10), 693-696. doi:http://dx.doi.org/10.1097/00005053-200210000-00006

Zanarini, M. C., Frankenburg, F. R., Dubo, E. D., Sickel, A. E., Trikha, A., Levin, A., \& Reynolds, V. (1998). Axis I comorbidity of borderline personality disorder. The American Journal of Psychiatry, 155(12), 1733-1739. Retrieved from http://ezproxy.lib.ryerson.ca/login?url=http://search.proquest.com/docview/619368184?acc ountid=13631

Zanarini, M. C., Frankenburg, F. R., Dubo, E. D., Sickel, A. E., Trikha, A., Levin, A., \& Reynolds, V. (1998). Axis II comorbidity of borderline personality disorder. Comprehensive Psychiatry, 39(5), 296-302. Retrieved from http://ezproxy.lib.ryerson.ca/login?url=http://search.proquest.com/docview/619372638?acc ountid=13631 